\title{
The small GTPase Rap1b negatively regulates neutrophil chemotaxis and transcellular diapedesis by inhibiting Akt activation
}

\author{
Sachin Kumar, ${ }^{1,2}$ Juying $\mathrm{Xu},{ }^{1,2}$ Rupali Sani Kumar, ${ }^{1,2}$ \\ Sribalaji Lakshmikanthan, ${ }^{3}$ Reuben Kapur, ${ }^{4}$ Matthew Kofron, ${ }^{5}$ \\ Magdalena Chrzanowska-Wodnicka, ${ }^{3}$ and Marie-Dominique Filippi ${ }^{1,2}$ \\ 'Division of Experimental Hematology and Cancer Biology, Cincinnati Children's Research Foundation, Cincinnati, $\mathrm{OH} 45229$ \\ 2University of Cincinnati College of Medicine, Cincinnati OH 45229 \\ ${ }^{3}$ Blood Research Institute, Blood Center of Wisconsin, Milwaukee, WI 53214 \\ ${ }^{4}$ Herman B Wells Center for Pediatric Research, Indiana University School of Medicine, Cancer Research Institute, \\ Indianapolis, IN 46202 \\ ${ }^{5}$ Division of Developmental Biology, Cincinnati Children's Research Foundation, Cincinnati, OH 45229
}

CORRESPONDENCE

Marie-Dominique Filippi:

Marie-Dominique.Filippi@

cchmc.org

Abbreviations used: ALI, acute lung injury; BAL, bronchoalveolar lavage; DRM, detergentresistant membrane; fMLP, formyl-methionyl-leucylphenylalanine; GAP, GTPaseactivating protein; GEFs, guanine nucleotide exchange factors; ICAM, intercellular adhesion molecule 1; ITIM, immunoreceptor tyrosine-based inhibitory motif; MAPK, mitogenactivated protein kinase; MFI, mean fluorescence intensity; MMP, metalloproteinase; PECAM, platelet endothelial cell adhesion molecule; Rap1, Ras proximity 1; SHP-1, SRChomology region 2 domaincontaining phosphatase-1; TEM, transendothelial migration; WCL, whole-cell lysate.

Neutrophils are the first line of cellular defense in response to infections and inflammatory injuries. However, neutrophil activation and accumulation into tissues trigger tissue damage due to release of a plethora of toxic oxidants and proteases, a cause of acute lung injury (ALI). Despite its clinical importance, the molecular regulation of neutrophil migration is poorly understood. The small GTPase Rap1b is generally viewed as a positive regulator of immune cell functions by controlling bidirectional integrin signaling. However, we found that Rap1b-deficient mice exhibited enhanced neutrophil recruitment to inflamed lungs and enhanced susceptibility to endotoxin shock. Unexpectedly, Rap $1 \mathrm{~b}$ deficiency promoted the transcellular route of diapedesis through endothelial cell. Increased transcellular migration of Rap1b-deficient neutrophils in vitro was selectively mediated by enhanced PI3K-Akt activation and invadopodia-like protrusions. Akt inhibition in vivo suppressed excessive Rap1b-deficient neutrophil migration and associated endotoxin shock. The inhibitory action of Rap1b on PI3K signaling may be mediated by activation of phosphatase SHP-1. Thus, this study reveals an unexpected role for Rap1b as a key suppressor of neutrophil migration and lung inflammation.

Neutrophils are the first line of cellular defense against infecting microorganisms and play a central role in innate immunity and inflammatory processes (Ley et al., 2007; Phillipson and Kubes, 2011). The influx of neutrophils into interstitial tissue and sites of inflammation play an essential role in pathogen elimination. However, it is also a cause of tissue damage when neutrophils aberrantly accumulate into tissues and release potent oxidants, proteases, and cationic peptides. The lungs are particularly exposed to neutrophil attack and uncontrolled activation of neutrophils into lungs can lead to acute lung injury (ALI; Brown et al., 2006; Grommes and Soehnlein, 2011; Phillipson and Kubes, 2011). In ALI, high circulating concentrations of proinflammatory cytokines, secreted by immune cells, often indicate risk of mortality, but therapeutics that mitigate cytokine activities have not improved patient survival (Brown et al., 2006). At present, despite conventional treatment, the mortality rate is $\sim 35 \%$. Therefore, knowledge of molecular regulation of neutrophil recruitment into tissue may provide beneficial outcomes in patients against such severe inflammation.

The neutrophil extravasation cascade into tissues is a multiple step process that involves tethering and rolling along the endothelium via L-selectin receptor. Subsequently, chemokineinduced $\beta 2$ integrin activation promotes firm

Q 2014 Kumar et al. This article is distributed under the terms of an AttributionNoncommercial-Share Alike-No Mirror Sites license for the first six months Noncommercial-Share Alike-No Mirror Sites license for the first six months
after the publication date (see http://www.rupress.org/terms). After six months it is available under a Creative Commons License (Attribution-NoncommercialShare Alike 3.0 Unported license, as described at http://creativecommons.org/ licenses/by-nc-sa/3.0/). 
adhesion of the neutrophils to the endothelium (Schenkel et al., 2004; Ley et al., 2007; Phillipson and Kubes, 2011).After arrest, neutrophils undergo actin-dependent polarization and lateral migration or crawling on endothelial cells in search for permissive sites, before final diapedesis out of blood vessels (Phillipson et al., 2006; Muller, 2011). Diapedesis or transendothelial migration (TEM) is the least explored step and can occur by two distinct routes: either through junctions between endothelial cells (the paracellular route) or directly through individual endothelial cells (the transcellular route; Feng et al., 1998; Schenkel et al., 2004; Phillipson et al., 2006; Carman et al., 2007; Carman and Springer, 2008; Sage and Carman, 2009; Shulman et al., 2009; Muller, 2011). Once at the site of inflammation, neutrophils release reactive oxygen species, proinflammatory cytokines, and various proteases that all contribute to tissue injury when the neutrophilic response remains uncontrolled. The signaling pathways that limit neutrophil responses are poorly understood.

Ras proximity 1 (Rap 1 ) belongs to the Ras superfamily of GTPases that cycle between GTP-bound active and GDPbound inactive forms through GEFs and GAPs (M'Rabet et al., 1998; Caron, 2003). The mammalian genome encodes two Rap1 genes, Rap1a and Rap1b, which are highly homologous and evolutionarily conserved. Mouse genetic studies have shown that Rap isoforms have both redundant and specific functions (Caron, 2003; Chrzanowska-Wodnicka et al., 2005; Li et al., 2007; Wittchen et al., 2011). Rap1 is historically known to control functional activation of integrins through inside-out signaling (Katagiri and Kinashi, 2012), and to promote cell adhesion, platelet aggregation, and phagocytosis in macrophages (Caron et al., 2000; Katagiri et al., 2003; ChrzanowskaWodnicka et al., 2005; Boettner and Van Aelst, 2009; Katagiri and Kinashi, 2012). Rap1 also controls actin polarization, as well as migration and homing into tissue, in lymphocytes (Shimonaka et al., 2003). Furthermore, Rap1 regulates angiogenesis (Lakshmikanthan et al., 2011) via cross talk between VEGFR2 with integrin $\alpha v \beta 3$. Rap1b is the predominant Rap1 isoform expressed in neutrophils, suggesting a preponderant role for Rap1b in these cells. Interestingly, CalDAGGEFI, which is a Rap1-GEF, appears to control neutrophil chemotaxis independently on integrin functions (Carbo et al., 2010). However, the role of Rap1b in neutrophil functions has not been studied.

Here, we reveal that Rap1b deficiency conferred enhanced susceptibility to endotoxin shock. In addition, Rap1b-deficient neutrophils manifested enhanced emigration to inflamed lungs. This response was associated with increased transcellular diapedesis in vitro. Interestingly, Rap1b loss induced elevated PI3K-p-Akt activity that promoted neutrophil invasiveness in vitro. Pharmacological inhibition of Akt activity completely reverted enhanced neutrophil migration and susceptibility to endotoxin shock. Our study characterizes a previously unknown role for Rap1b as a physiological suppressor of neutrophil emigration. This may represent an unappreciated regulatory pathway of neutrophil-related aberrant inflammatory responses.

\section{RESULTS}

A critical event of neutrophil migration is the adoption of a polarized shape. During neutrophil polarization, the plasma membrane reorganizes into detergent-resistant membrane (DRM) domains at the uropod. Recently, we showed that the small Rho GTPase Cdc42 regulates neutrophil polarity by controlling the composition of DRMs (Kumar et al., 2012). Proteomics analysis of WT and Cdc42 $2^{-/-}$neutrophil DRM fractions revealed that the GTPase Rap $1 \mathrm{~b}$ was present in the DRM of WT but not Cdc42-/- neutrophils (not depicted), which was confirmed by immunoblotting (Fig. 1 A). Consistent with DRM association, Rap1b was enriched at the uropod (unpublished data), suggesting the participation of Rap1b signaling in neutrophil migration.Yet, the roles for Rap $1 \mathrm{~b}$ in neutrophil functions and inflammation remain largely unknown.

\section{Rap1b deficiency enhances neutrophil recruitment into inflamed lungs}

We first examined the role of Rap1b in neutrophil recruitment in vivo using a well-established model of LPS-driven ALI. Because Rap1b is expressed in all tissues, including endothelial cells, we used adoptive transplantation of BM cells from Rap $1 \mathrm{~b}^{-/-}$and control WT mice into lethally irradiated C57BL/6 WT mice to allow selective Rap1b deletion in blood cells (Filippi et al., 2007). $5 \mathrm{wk}$ after hematopoietic reconstitution, Rap1b proteins were absent in neutrophils isolated from Rap $1 b^{-/-}$reconstituted mice (Fig. 1 B). In these cells, expression of total Rap1 protein was low, suggesting that Rap1a expression does not compensate for Rap1b loss (Fig. 1 B), as previously reported (Awasthi et al., 2010; Carbo et al., 2010). The total white blood count, including neutrophils, was normal in WT and Rap $1 \mathrm{~b}^{-1-}$ reconstituted animals (unpublished data). Unexpectedly, bronchoalveolar lavage (BAL) of $\mathrm{Rap}_{1 \mathrm{~b}^{-/-}}$reconstituted mice that were inoculated with LPS contained more neutrophils than similarly challenged control mice (Fig. 1 C). Higher rate of hemorrhage, as indicated by increased red cell count (Fig. 1 C), and increased protein content (Fig. 1 D) were also noted in BAL from $\mathrm{Rap}_{1 \mathrm{~b}^{-/-}}$mice, whereas macrophages were comparable between the genotypes (Fig. 1 C). Lung histology showed enhanced neutrophil infiltration into interstitial tissues and increased neutrophil numbers in the alveoli of $\mathrm{Rap} \mathrm{b}^{-/-}$reconstituted mice, compared with WT mice (Fig. 1 E). An adoptive transfer of WT and Rap1b ${ }^{-/-}$neutrophils labeled with 2 different dyes confirmed the neutrophil cell-intrinsic nature of Rap1b function, as more $\mathrm{Rap} 1 \mathrm{~b}^{-/-}$neutrophils emigrated into inflamed lung alveoli than WT neutrophils (Fig. 1 F). Finally, Rap $1 b^{-1-}$ reconstituted mice were more susceptible to higher dose of intraperitoneal LPS challenge than WT controls (Fig. 1 G). Hence, Rap1b is, surprisingly, a negative regulator of neutrophil emigration into lungs.

\section{Rap1b deficiency increases neutrophil transmigration}

To further investigate the role of Rap1b in neutrophil migration, chemotaxis toward fMLP was examined in Zigmond chamber using time lapse microscopy. In contrast to enhanced 

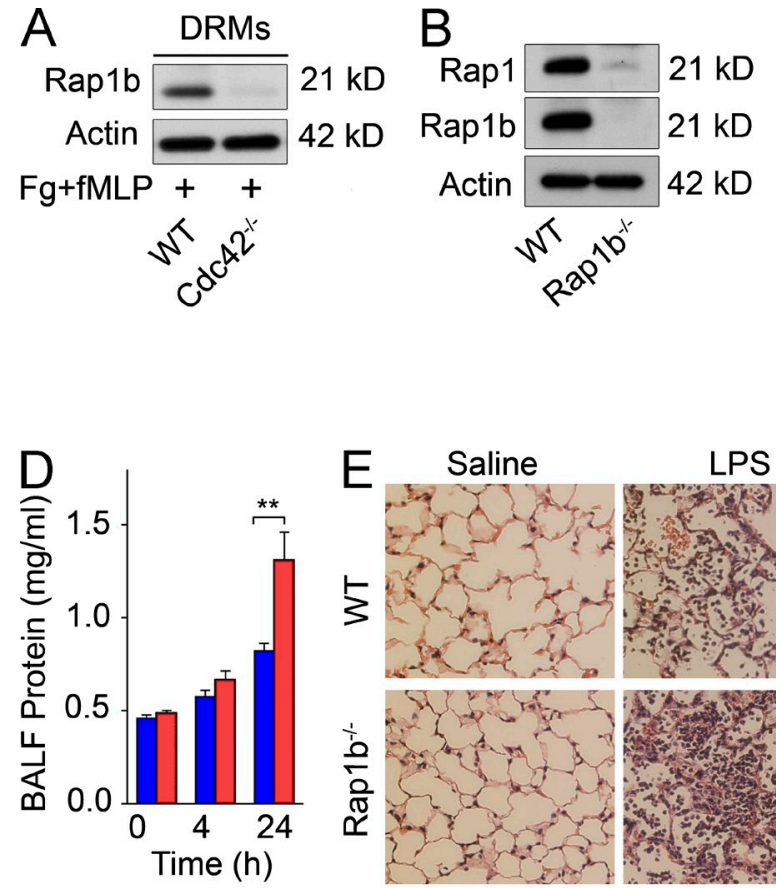

Saline
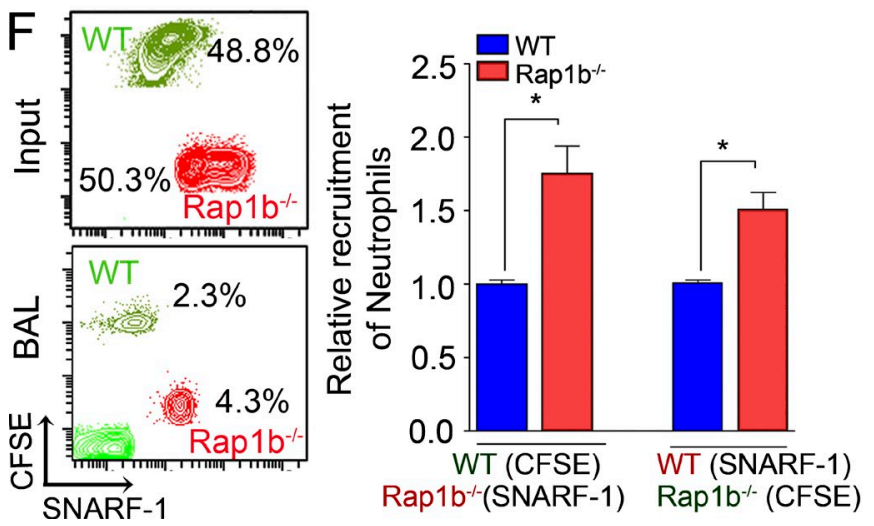
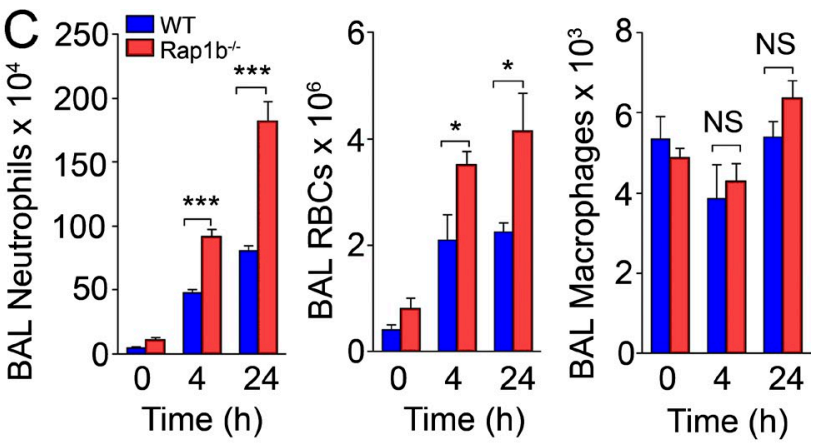
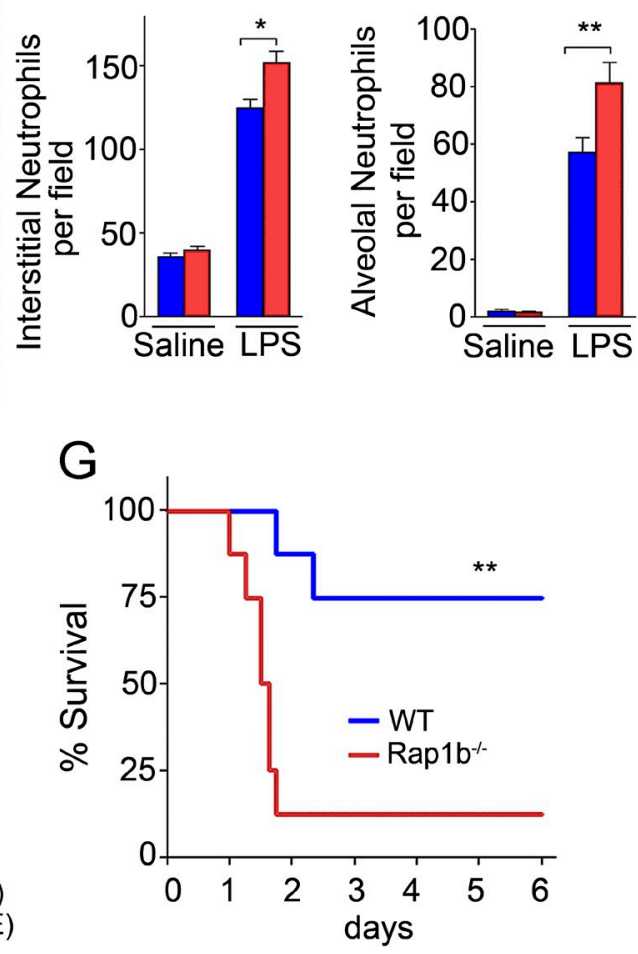

Figure 1. Loss of Rap1b leads to increased neutrophil infiltration to inflamed lungs. (A) Immunoblot analysis of Rap1b in the DRMs of WT and Cdc42 $2^{-1-}$ neutrophils. (B) Immunoblotting of neutrophil lysates from mice reconstituted with WT and Rap 16 ${ }^{-1-}$ BM using anti-Rap1b, anti-total Rap1, and $\beta$-actin antibodies. Blots are representative of three independent experiments. (C) BAL analysis of mice reconstituted with WT or Rap16 ${ }^{-1-}$ hematopoietic cells that were challenged with interstitial saline or LPS $(1.25 \mathrm{mg} / \mathrm{kg})$. Numbers of neutrophils, RBCs, and macrophages recovered in BAL at 4 and $24 \mathrm{~h}$ after LPS challenge; $n=4$ mice per group; two independent experiments. (D) Total protein analysis of BAL fluid (BALF) at 4 and $24 \mathrm{~h}$ after LPS challenge. (E) Hematoxylin and eosin staining of lung sections $24 \mathrm{~h}$ after saline or LPS challenge. Bar, $20 \mu \mathrm{m}$. Quantification of neutrophil infiltration in interstitial tissue and alveolar spaces using lung sections from $n=6$ mice per group from three independent experiments. (F) Relative recruitment of CSFE and SNARF1 labeled and adoptively transferred WT and Rap16-1- neutrophils in BAL of LPS challenged mice. Data are representative of three independent experiments with 3 mice each group ( $C-F$; mean $\pm S D ;{ }^{*}, P<0.05 ;{ }^{* *}, P<0.01 ;{ }^{* * *}, P<0.001$; NS, not significant using unpaired Student's $t$ test). (G) Survival of mice ( $n=8$ per genotype) injected i.p. with $20 \mathrm{mg} / \mathrm{kg}$ LPS. ${ }^{*}, \mathrm{P}=0.00259$, log-rank test. Representative of two independent experiments.

neutrophil emigration to lungs in vivo, time lapse analysis revealed that Rap $1 b^{-1-}$ neutrophils exhibited a modest decreased ability to efficiently migrate up the chemotactic gradient (Fig. 2 A and Video 1). Rap $1 b^{-1-}$ cells extended transient multiple pseudopodia and made frequent turns leading to a $25 \%$ reduction in straightness relative to WT cells (Fig. $2 \mathrm{~A}$ and Video 2), as previously reported (Carbo et al., 2010). However, the speed of migration was $15 \%$ increased whereas chemoattractant sensing of Rap $1 b^{-/-}$was similar to that of WT because, overall, the cells migrated toward the chemotactic gradient. To further understand the role of Rap1b in neutrophil migration, we used Boyden chamber assays in response to neutrophil chemokines, AMLP and MIP2. Random migration (chemokinesis) was assessed in a uniform AMLP concentration in both wells of the chamber, whereas directed migration (chemotaxis) was assessed in a gradient in which $\mathrm{AMLP}$ was placed only in the lower chamber. Interestingly, $\mathrm{R}_{\mathrm{ap}} 1 \mathrm{~b}^{-/-}$neutrophil migration to AMLP or MIP2 in both chemotaxis and chemokinesis 

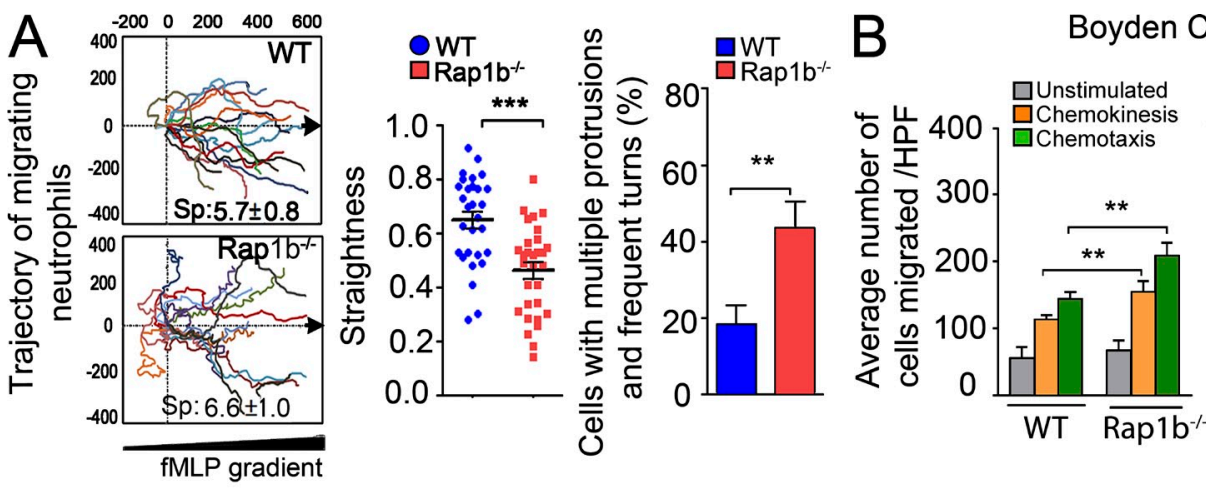

Boyden Chamber- fMLP
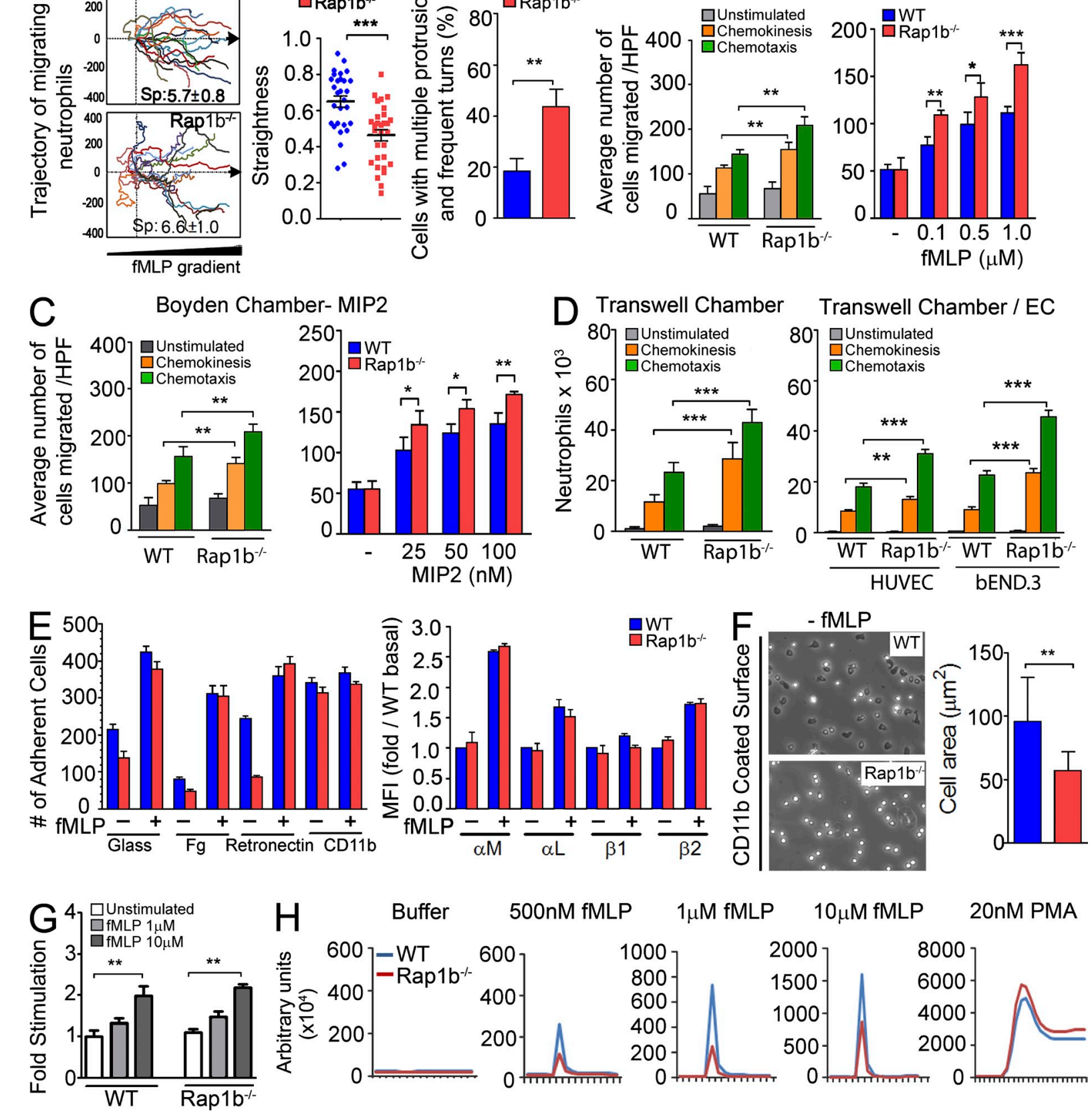

Figure 2. Rap $1 b^{-I-}$ neutrophils exhibit enhanced chemokinesis and chemotaxis. (A) Analysis of neutrophil migration using time lapse video microscopy in a gradient of fMLP in Zigmond chamber. Cell trajectory analysis; the schema represents the migration trajectory of cells moving up fMLP gradient for $20 \mathrm{~min}$. Speeds ( $\mathrm{Sp}=\mu \mathrm{m} / \mathrm{min}$ ) of migration are indicated at the bottom. Mean $\pm S D ; n=60$ cells. Scatter plot of straightness of migration from 30 individual cells, representative of 3 independent experiments. Bar graph represents the percentage of cells exhibiting frequent changes in direction. Data are from 80 cells (mean $\pm S D ;{ }^{*}, \mathrm{P}<0.05 ;{ }^{* *}, \mathrm{P}<0.01 ; * *, \mathrm{P}<0.001 ; 3$ independent experiments). (B and $\mathrm{C}$ ) Chemokinesis (uniform chemokine concentration) and chemotaxis (chemokine gradient) analysis of neutrophils using a Boyden chamber with $1 \mu \mathrm{M}$ fMLP, $100 \mathrm{nM}$ MIP2, or differential concentration of chemokines. The histogram represents the number of migrated neutrophils per field using a $40 \times$ objective (mean $\pm S D ;{ }^{*}, P<0.05 ;{ }^{* *}, P<0.01$; ${ }_{* * *}^{*}, \mathrm{P}<0.001$; representative of 3 independent experiments). (D) Neutrophil migration using Transwell-coated with fibrinogen (Fg) or endothelial cells (HUVECs and bEND.3) grown on Transwell filters in uniform concentration or in a gradient of $10 \mu \mathrm{M} \mathrm{fMLP.} \mathrm{Histogram} \mathrm{represents} \mathrm{the} \mathrm{total} \mathrm{number} \mathrm{of}$ migrated neutrophils recovered from the bottom well (mean $\pm \mathrm{SD} ; n=3 ;{ }^{* *}, \mathrm{P}<0.01$; ${ }^{* * *}, \mathrm{P}<0.001$; using unpaired Student's $t$ test; 3 independent experiments). (E) Adhesion analysis of WT and Rap $1 b^{-1-}$ neutrophils that were stimulated with fMLP and plated on diverse integrin ligands. Expression of integrins on WT and Rap $1 b^{-1-}$ neutrophils with or without fMLP stimulation, as quantified using flow cytometry (mean \pm SD; $n=3$ independent experiments). (F) Images and quantification of spreading from minimum 50 WT and Rap $1 b^{-1-}$ neutrophils that were plated on CD11b-coated plates without fMLP. Bar, $10 \mu \mathrm{m}$. Mean \pm SD; $n=3$ independent experiments **, $P<0.01$. (G) Superoxide generation analysis in suspension by using flow cytometry and 
assays was higher than WT cells (Fig. 2, B and C). Increased chemotaxis of Rap1b $\mathrm{b}^{-/-}$neutrophils was also observed with a range of chemokine concentrations (Fig. 2, B and C). Migration was examined in Transwells coated with fibrinogen (Fg), a $\alpha M \beta 2$ integrin ligand, to investigate transmigration or Transwell coated with murine (bEND.3) or human (HUVEC) endothelial cells to monitor the role of Rap1b in transendothelial migration (Gerard et al., 2009). Enhanced migratory responses of Rap $1 b^{-/-}$neutrophils to fMLP were seen in both assays (Fig. 2 D), and we noted higher neutrophil TEM across bEND.3 cells than HUVECs. Together, although straightness of migration may be modestly decreased, Rap $1 b^{-/-}$neutrophils exhibited enhanced transendothelial migration. This phenotype was specific to Rap1b isoform. Rap1a ${ }^{-/-}$neutrophils transmigrated similarly to WT cells, in Transwell assay and in vivo into lungs after neutrophil adoptive transfer (unpublished data), suggesting that Rap1a is dispensable for neutrophil migration.

Neutrophil migration across the endothelial barrier depends on chemokine release and on interaction with the endothelium through adhesion molecules, including integrins. At the site of inflammation, chemokine and integrin stimulation triggers various neutrophil responses, including spreading, oxidative burst, and degranulation, which are known as adhesion-dependent responses. Because Rap1 proteins were initially identified to regulate cell adhesion by controlling chemokine-induced inside-out integrin signaling (Caron et al., 2000; Katagiri et al., 2003), we then examined static adhesion to diverse extracellular matrix (ECM)-coated surfaces in response to the neutrophil chemokine PMLP.After fMLP stimulation, Rap1b ${ }^{-/-}$neutrophil adhesion on any tested surface was comparable to WT (Fig. 2 E). Consistently, regulated expression of different integrin subunits, including $\alpha \mathrm{L}$ (LFA-1/CD11a), $\alpha \mathrm{M}$ (Mac-1/CD11b), $\beta 1$ (CD29), and $\beta 2$ (CD18), in Rap1b ${ }^{-1-}$ neutrophils were comparable to WT neutrophils (Fig. 2 E). Hence, in neutrophils, Rap1b appears not to be critical for integrin-mediated adhesion. However, we noted a significant reduction in $\mathrm{Rap} 1 \mathrm{~b}^{-/-}$ neutrophil spreading onto CD11b-coated plates relative to WT (Fig. 2 F). fMLP-induced intracellular superoxide production was comparable between the genotypes (Fig. 2 G). However, it was lower in fibrinogen-mediated adherent Rap $1 b^{-1-}$ than in WT neutrophils after fMLP stimulation, but not with PMA that mediates integrin-independent superoxide production (Fig. $2 \mathrm{H}$ ). Hence, Rap1b seems dispensable for static adhesion, but critical for adhesion-dependent neutrophil responses.

\section{Rap1b disruption enhances transendothelial migration through transcellular diapedesis}

During the extravasation cascade, initial neutrophil adhesion onto the endothelium is followed by lateral crawling to find the nearest endothelial cell junction and permissive sites for transmigration (Ley et al., 2007). To examine in more detail the role of Rap1b during transendothelial migration, we used a 3D transmigration model using either HUVECs (unpublished data; Schenkel et al., 2004; Muller, 2011) or murine endothelial cells (Gerard et al., 2009) that recapitulate these critical steps. Neutrophils were seeded onto nonactivated or LPS-activated bEND. 3 cells that were grown on collagen gels (Fig. 3 A). Under these conditions, LPS stimulates expression of ICAM, a $\beta 2$ integrin ligand, on endothelial cells (Fig. 3 A), triggering neutrophil adhesion and transmigration (Sikorski et al., 1993; Yang et al., 2005). Rap1b ${ }^{-/-}$neutrophil adhesion to activated endothelial cells was comparable to that of WT (Fig. 3 B). In contrast, significantly less $\mathrm{Rap} 1 \mathrm{~b}^{-/-}$than WT neutrophils $(64.5 \pm 2.3$ vs. $83.0 \pm 2.1)$ were found at the endothelial cell junctions (Fig. 3 C). Remarkably, transendothelial migration of Rap $1 b^{-1-}$ neutrophils was persistently increased compared with WT neutrophils (Fig. 3 D). The integrity of endothelial junctions was examined using PECAM staining and dextran permeability assay (unpublished data). Similar enhanced transendothelial migration was observed when Rap $1 b^{-/-}$neutrophils were plated on HUVECs (unpublished data). These results confirmed enhanced transmigration of Rap $1 b^{-/-}$neutrophils.

Neutrophil diapedesis can occur by two distinct routes, either between two endothelial cells, i.e., a paracellular route, or directly through them, i.e., a transcellular route (Carman et al., 2007; Sage and Carman, 2009; Muller, 2011). Enhanced transcellular migration could account for increased transmigration of $\mathrm{Rap} 1 \mathrm{~b}^{-/-}$neutrophils while the cells remained away from the endothelial junction. To examine the nature of diapedesis, transmigrating neutrophils onto HUVEC (unpublished data) or mouse endothelial cells were stained for VE-Cadherin to visualize endothelial cell junctions and for Gr-1 to identify neutrophils. ICAM-1 staining allows identification of the so-called transmigration cup, which is comprised of endothelial ICAM-1-enriched projections surrounding transmigrating leukocytes that occur during diapedesis (Carman et al., 2003; Carman and Springer, 2004). A representative example of each migratory route, identified using VE-Cadherin, ICAM-1, and Gr-1 staining, is depicted in Fig. 4 A (Carman et al., 2003; Carman and Springer, 2004). Only $5-10 \%$ of WT neutrophils used the transcellular route of diapedesis (Fig. 4 A). Interestingly, up to $30-35 \% \mathrm{Rap} 1 \mathrm{~b}^{-/-}$ neutrophils transmigrated via the transcellular route (Fig. 4 A). More transmigratory cups were observed during $\mathrm{Rap} 1 \mathrm{~b}^{-/-}$ transmigration than in WT counterparts (Fig. 4 B). Overall, the total number of cells that transmigrated was higher in Rap1b ${ }^{-1-}$ than WT neutrophils (Fig. 3 B and Fig. 4 A). Similar results were obtained across HUVECs (unpublished data). Therefore, Rap $1 b^{-1-}$ neutrophils were found away from the endothelial junctions and exhibited increased transmigration and transcellular diapedesis in vitro.

DCF-DA probe. Mean \pm SD; $n=3$ independent experiments; ${ }^{* *}, P<0.01$ (unpaired Student's $t$ test). (H) Superoxide generation kinetics from neutrophils in 96-well plates under adherent condition after stimulation with different concentration of fMLP or PMA. Chemiluminescence of L012 was measured for 20 min using GloMax-96 Microplate Luminometer (Promega). $n=3$ independent experiments. 

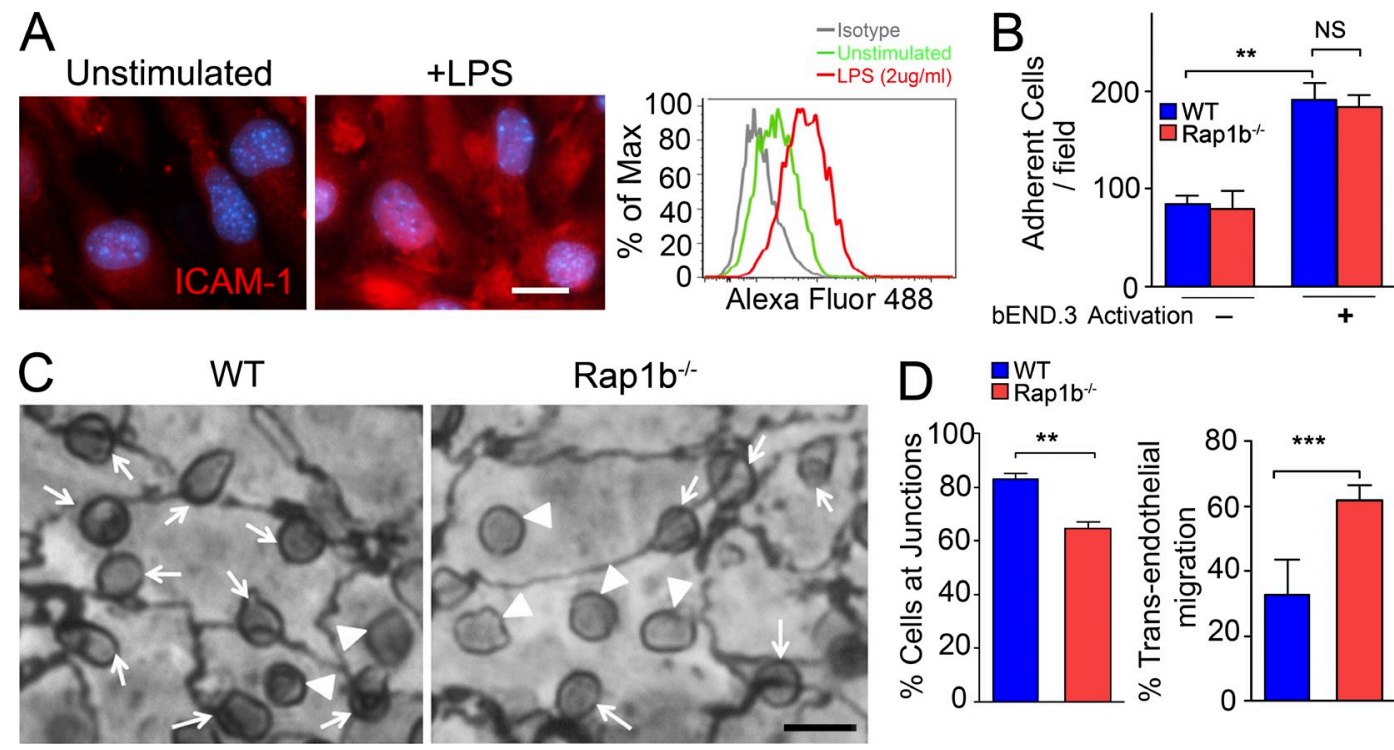

Figure 3. Rap1b loss promotes transendothelial migration in 3D model. (A) Immunofluorescence images of ICAM-1 (red) and nuclei (blue) on surface of bEND.3 cells with or without stimulation with LPS $(2 \mu \mathrm{g} / \mathrm{ml})$ treatment for $18 \mathrm{~h}$. Bar, $10 \mu \mathrm{m}$. Flow cytometry histogram showing ICAM expression on unstimulated and stimulated bEND. 3 that were stained with anti-ICAM-1 and Alexaflour-488 conjugated secondary antibody ( $n=3$ independent experiments). (B) The bar graph represents number of cells per field adhered to bEND.3 grown on collagen and activated without or with LPS (mean \pm SD, $n=4$ independent experiments). (C) Representative images showing the neutrophil location after adhesion and locomotion onto LPS-activated bEND.3. Bar, $10 \mu \mathrm{m}$. Images show the location of neutrophils on the surface of junctions (arrows) and on bEND.3 cell body, a distance away from junctions (arrowheads). (D) The bar graph represents the percentage of cells present at bEND.3 junctions and the percentage of cells transmigrated underneath bEND.3. Mean $\pm S D ; n=4$ independent experiments. ${ }^{*}, \mathrm{P}<0.01 ;{ }^{* * *}, \mathrm{P}<0.001 ; \mathrm{NS}$, not significant using unpaired Student's $t$ test.

\section{Enhanced and sustained actin polymerization in Rap $1 b^{-/-}$neutrophils}

Podosomes or invadopodia-like actin protrusions are important for transcellular diapedesis (Carman et al., 2007). These actin structures are ECM-degrading protrusions that release matrix metalloproteinases (MMPs) to penetrate into tissue (Linder and Aepfelbacher, 2003; Buccione et al., 2004). Filamentous actin protrusions were first analyzed on AMLP-stimulated neutrophils and plated on fibrinogen. Remarkably, although WT neutrophils had a single lamellipodia of F-actin at the cell front, Rap $1 b^{-/-}$neutrophils extended abnormal lateral F-actin protrusions (Fig. 5, A and B). F-actin was also quantified by flow cytometry. F-actin peaked within $30 \mathrm{~s}$ of fMLP stimulation both in WT and Rap1b $\mathrm{b}^{-/-}$neutrophils (Fig. 5 C). Rap1b ${ }^{-1-}$ neutrophils exhibited a prolonged $\mathrm{F}$-actin response to $\mathrm{AMLP}$ compared with WT neutrophils, with sustained F-actin polymerization after $1 \mathrm{~min}$ of stimulation. This is consistent with the formation of a secondary wave of F-actin organization, which has been linked to invasive migratory behavior (Fig. 5, $\mathrm{C}$ and D). Rap1b ${ }^{-/-}$neutrophils also manifested increase in $\left[\mathrm{Ca}^{2+}\right]$ i release to low fMLP concentration (Fig. 5 E). Thus, loss of Rap1b leads to exaggerated F-actin protrusions.

\section{Enhanced matrix degradation ability in Rap $1 b^{-/-}$neutrophils}

To determine whether the abnormal actin protrusions of $\mathrm{Rap}_{\mathrm{b}} \mathrm{b}^{-/-}$were invasive in nature, we used coverslips coated with fluorochrome-conjugated gelatin matrices. The local proteolytic activity was identified by the appearance of black holes in fluorochrome-conjugated gelatin matrices (Artym et al., 2006). fMLP-stimulated Rap $1 b^{-/-}$neutrophils created more holes that were larger in size than those made by WT cells (Fig. 6 A). Likewise, using MMP zymography, we observed higher MMPs release from Rap1b $\mathrm{b}^{-/-}$neutrophils than WT neutrophils, in a time-dependent manner (Fig. 6 B). Transmission electron microscopy confirmed increased podosome-like structures in Rap $1 \mathrm{~b}^{-/-}$neutrophils that penetrated deeper into endothelial surfaces than WT cells (Fig. 6 C). This was supported by observation of longer and more protrusive microvilli on surface of Rap $1 b^{-/-}$neutrophils than WT controls (Fig. 6 D). These results suggest that Rap1b inhibits invasive F-actin protrusions to limit transcellular diapedesis in vitro.

\section{Loss of Rap1b leads to enhanced Akt and Ptdlns $(3,4,5)$ P3 signaling}

F-actin protrusions are highly dependent on PI3K signaling generating inositol lipid phosphatidylinositol 3,4,5-trisphosphate (PtdIns [3,4,5]P3 or PIP3; Cicchetti et al., 2002; Stephens et al., 2002). Importantly, cellular invasion is strongly dependent on Akt signaling, a key downstream target of PI3K-PIP3 cascade (Stephens et al., 2002; Chin and Toker, 2009), To examine the role of PI3K signaling in our model, we first examined the localization of $\mathrm{AMLP}$-elicited $\mathrm{PIP}_{3}$ production of cells plated on fibrinogen. As expected, PIP3 was localized at the leading edge of fMLP-stimulated and polarized WT neutrophils (Fig. 7 A). Conversely, PIP3 signals were higher in Rap1b $\mathrm{b}^{-1-}$ cells and 

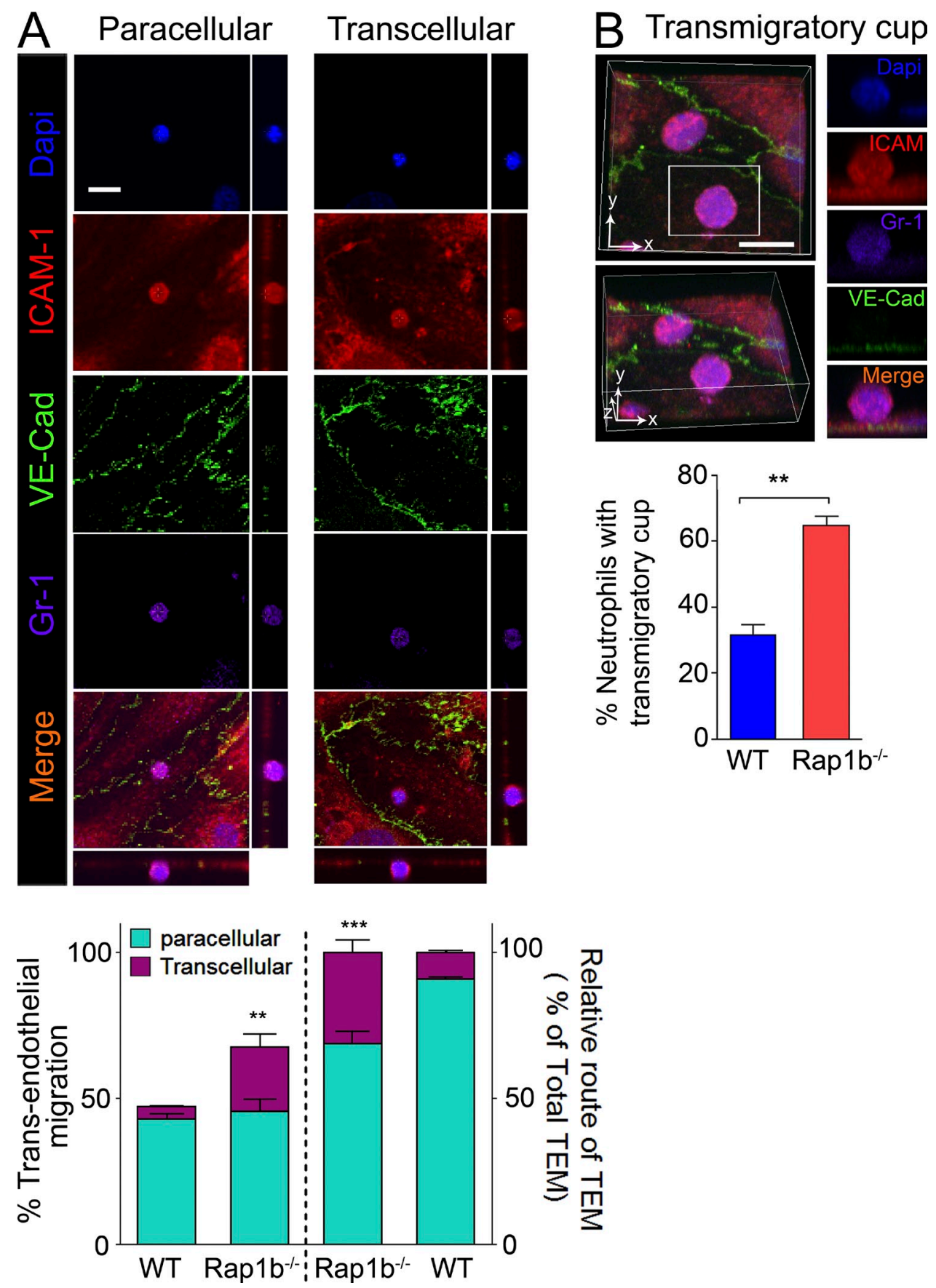

Figure 4. Rap1b loss promotes transendothelial migration via transcellular route. $(A, t o p)$ Representative immunofluorescence images showing paracellular and transcellular migration of neutrophils, identified using VE-cadherin, ICAM-1, and Gr-1 staining. Bar, 20 um. (bottom) Percentage of WT and Rap $1 b^{-1-}$ neutrophils showing diapedesis via paracellular and transcellular route and relative percent neutrophils using paracellular and transcellular route (mean $\pm S D)$. Data are cumulative from 4 independent experiments with more than 750 cells showing transendothelial migration. (B, top) Representative images of transmigratory cups, percentage of WT and Rap $1 b^{-1-}$ neutrophils encircled with ICAM-rich transmigratory cups. Mean \pm SD. $n=3$ independent experiments. ${ }^{* *}, P<0.01 i^{* * *}, P<0.001$; NS, not significant using unpaired Student's $t$ test. Bar, $10 \mu m$.

enriched all around the cells (Fig. 7 A). Consistently, Akt phosphorylation was more substantially increased in Rap $1 \mathrm{~b}^{-1-}$ neutrophils than in WT cells in response to $\mathrm{AMLP}$ and integrin activation (Fig. 7 B) or fMLP alone (Fig. 7 C), as shown in other cells (Lou et al., 2002). On the other hand, MAPK signaling pathways, which are reportedly important for neutrophil migration (Liu et al., 2012), remained unchanged in Rap1b ${ }^{-/-}$ neutrophils (Fig. 7 D). Screening of different signaling pathways important for matrix degradation/invasion using pharmacological inhibitors further suggested a critical role of PI3K-Akt 

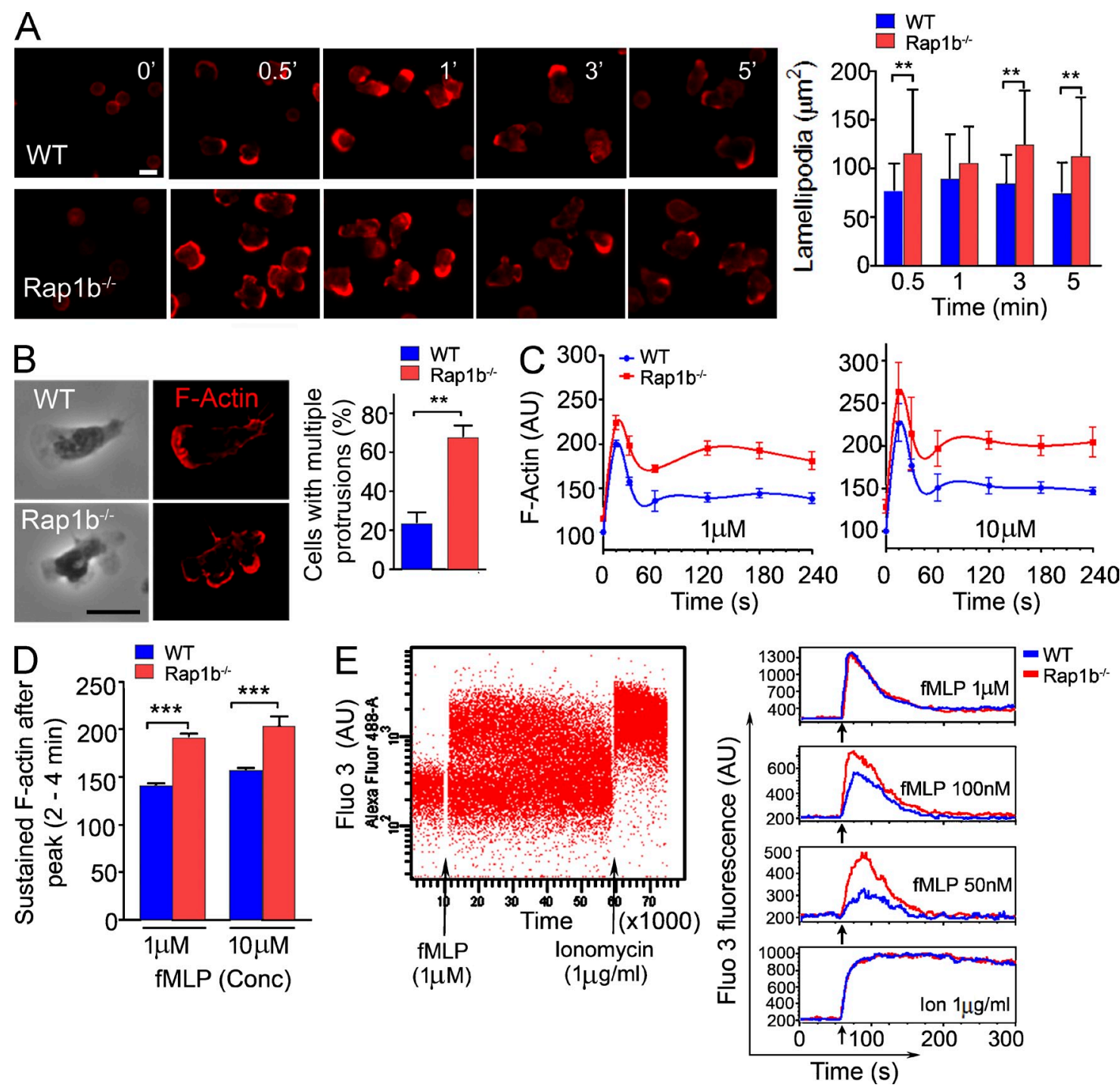

Figure 5. Rap $1 \mathbf{b}^{-I-}$ neutrophils exhibit enhanced actin protrusions. (A) Kinetics of fMLP-induced F-actin assembly under adhesion. Representative images of WT and Rap $1 b^{-1-}$ neutrophils that were stimulated with fMLP on fibrinogen-coated slides for the indicated time and stained with rhodamine/phalloidin (in red). Bar, $10 \mu \mathrm{m}$. Bar graphs show lamellipodium area of 60 cells that are representative of 3 independent experiments. Mean \pm SD; ${ }^{* *}, P<0.01$ using an unpaired Student's $t$ test. (B) Immunofluorescence analysis of F-actin in WT and Rap $1 b^{-1-}$ neutrophils that were stimulated with $\mathrm{fMLP}$ and plated on a fibrinogen-coated surface. Bar, $10 \mu \mathrm{m}$. Bar graph represents the percentage of cells with multiple protrusions. Mean $\pm S D_{i}{ }^{* *}, P<0.01$ using an unpaired Student's $t$ test; $n=3$ independent experiments. (C) Kinetics of F-actin polymerization in WT and Rap $1 b^{-1-}$ neutrophils after fMLP stimulation in suspension using flow cytometry with respect to unstimulated WT neutrophil fluorescence ( $n=3$ independent experiments). (D) Sustained or second phase of F-actin measured as the percentage of phalloidin fluorescence at 120-240 $\mathrm{s}$ to the fluorescence of unstimulated WT neutrophils. ${ }^{* *}, \mathrm{P}<0.001$. Data are mean \pm SD representative of three independent experiments per-

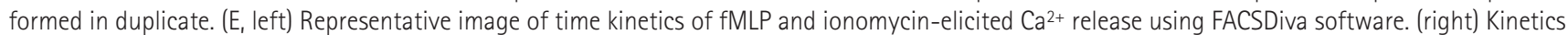
analysis of intracellular $\mathrm{Ca}^{2+}$ release in WT (blue) and Rap $1 b^{-1-}$ (red) neutrophils using $\mathrm{Ca}^{2+}$-sensitive dyes Fluo-3 in calcium-containing buffer in response to differential concentration of fMLP or ionomycin. Data were analyzed by FlowJo software and are representative of three independent experiments.

signaling in enhanced $\mathrm{Rap} 1 \mathrm{~b}^{-/-}$matrix degradation. In addition, enhanced matrix degradation was also dependent on Rac activity, a known regulator of actin polymerization (Cicchetti et al., 2002), and MMP activities (unpublished data). These findings suggest that Rap1b prevents neutrophil transcellular migration by limiting PI3K-Akt-dependent invasive actin protrusions in vitro.
Pharmacological inhibition of Akt activation rescued Rap $1 b^{-I-}$ neutrophil phenotype

To examine the contribution of Akt signaling to Rap1b-null phenotype, we used a small molecule Akt inhibitor, MK2206 (Hirai et al., 2010). MK-2206 treatment successfully inhibited Akt phosphorylation in $\mathrm{Rap} 1 \mathrm{~b}^{-/-}$and WT cells (Fig. 7 E). Remarkably, MK-2206 treatment completely 

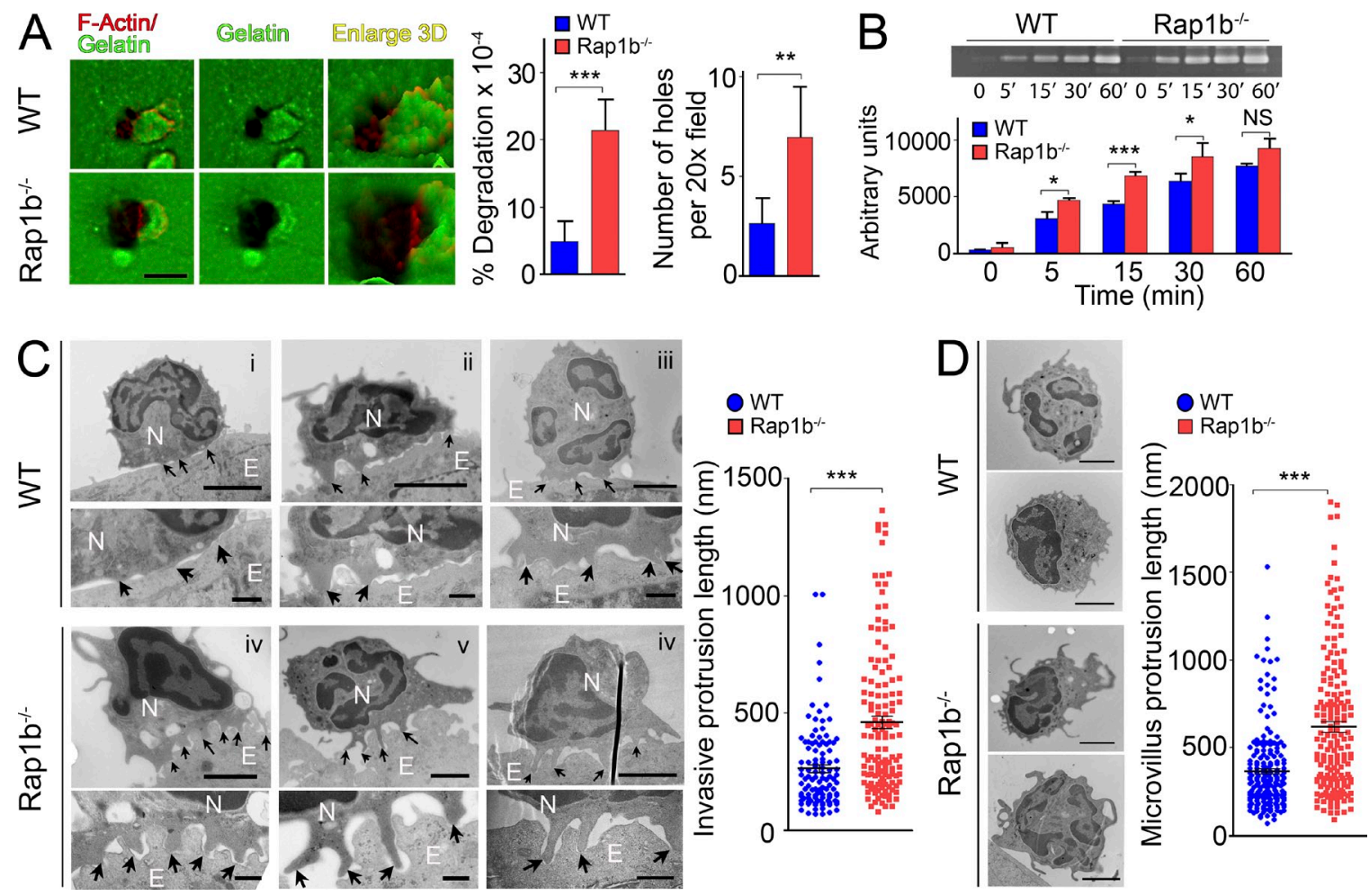

Figure 6. Rap1 $b^{-I-}$ neutrophils exhibit enhanced ECM degradation and invadopodia. (A) ECM degradation analysis of WT and Rap1b-1- neutrophils using Oregon green-labeled gelatin surface. Representative images of gelatin (green) and neutrophil stained for F-actin (red). Bar graphs represent percent degradation and number of holes per $20 \times$ field. Mean $\pm S D$, representative of 5 independent experiments. ${ }^{* *}, P<0.01 ;{ }^{* * *}, P<$ 0.001 ; using unpaired Student's $t$ test). Bar, $10 \mu \mathrm{m}$. (B) Kinetics of MMP-2 release by WT and Rap16 $b^{-1-}$ neutrophils after fMLP stimulation in suspension. Data are mean $\pm \mathrm{SD} ; n=3$ independent experiments. ${ }^{*}, \mathrm{P}<0.05 ;{ }^{* * *}, \mathrm{P}<0.001$; NS, not significant using unpaired Student's $t$ test. (C) Electron microscopic analysis of neutrophil invasive protrusions on the surface or invading the endothelial cells, highlighted by black arrows. Scatter plot represents the length of podosome/invadopodia structures on or invading into endothelial cells in nanometers; data are from 3 experiments with >30 cells having 120 invasive protrusions Bars: $2 \mu \mathrm{m}$ (i-vi); $500 \mathrm{~nm}$ (enlarged images in bottom row). (D) Electron microscopic analysis of protrusive microvilli on surface of WT and Rap $1 b^{-1-}$ neutrophils that were incubated on activated endothelial cells for 10 min, two examples of representative images for each genotype. Bars, $2 \mu \mathrm{m}$. Scatter plot represents length of microvillus protrusion in nanometer (nm). Data are from 25 WT neutrophils with 204 protrusive microvilli and 23 Rap $1 b^{-1-}$ neutrophils with 187 protrusive microvilli from at least 3 independent experiments. , ${ }^{* *}, P<0.001$ using unpaired Student's $t$ test.

reversed elevated TEM across mouse endothelial cells of Rap1b ${ }^{-/-}$neutrophils to WT levels (Fig. $8 \mathrm{~A}$ ). It reduced ECM degradation of Rap1 ${ }^{-/-}$neutrophils, and inhibited their multiple protrusions (Fig. 8, B and C). Furthermore, almost all Rap1b ${ }^{-/-}$cells treated with MK-2206 were found at the endothelial cell junctions (Fig. 8 D). However, MK2206 had little effect on WT neutrophil transmigration. We also tested the effect of Src kinase inhibitor PP2, which inhibits neutrophil crawling and transmigration processes (Carman et al., 2007; Gerard et al., 2009). Interestingly, PP2, like MK2206, completely rescued Rap1b ${ }^{-/-}$phenotypes (Fig. $8 \mathrm{~A}$ ), but it also inhibited elevated p-Akt (Fig. 7 E). Remarkably, MK2206 pretreatment completely reversed LPS-induced $\mathrm{Rap}_{1} \mathrm{~b}^{-/-}$neutrophil emigration into lung alveoli in vivo to WT levels (Fig. $8 \mathrm{E}$ ) and rescued survival of Rap $1 \mathrm{~b}^{-/-}$mice challenged with lethal dose of LPS, without any effect on WT (Fig. 8 F). Thus, Akt signaling is a major pathway mediating Rap1b loss phenotype.
Rap1b inhibits Akt activation via CD11b outside-in signaling The neutrophil crawling and TEM steps are highly $\alpha M \beta_{2}$ integrin-dependent (Phillipson et al., 2006). Because Rap1b controls some adhesion-dependent cellular functions, including superoxide production (Fig. 2), we investigated whether Rap1b migratory behavior was CD11b-dependent. Because CD11b associates with the DRMs at the cell uropod during migration (Kumar et al., 2012), and Rap1b can localize at the cell uropod and associate with DRMs, we examined the protein composition of DRMs of Rap1 $\mathrm{b}^{-/-}$and CD11b $\mathrm{b}^{-/-}$neutrophils. CD11b was present in the DRM fraction of $\mathrm{Rap} 1 \mathrm{~b}^{-/-}$neutrophils. However, Rap1b was completely absent in CD11b ${ }^{-1-}$ DRMs (Fig. 9 A). Rap1b protein levels in whole-cell lysates (WCLs) of CD11b ${ }^{-/-}$PMN were comparable to WT cells (Fig. 9 A). We thus hypothesized that Rap1b may act downstream of CD11b to limit CD11b-induced Akt signals and associated matrix degradation. In support of this notion, we found Akt phosphorylation to be highly CD11b dependent. Akt phosphorylation was 
A
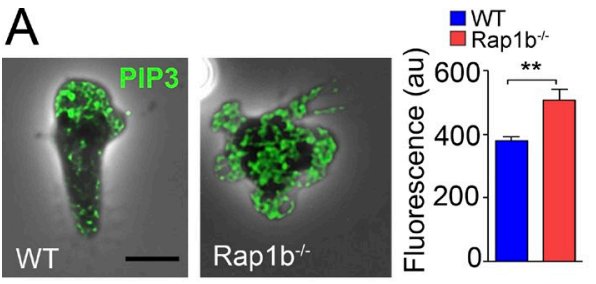

B

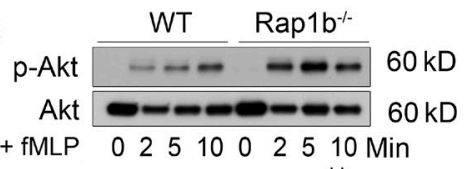

$\mathrm{Fg}+\mathrm{fMLP} \quad 0 \quad 2510022510 \mathrm{Min}$

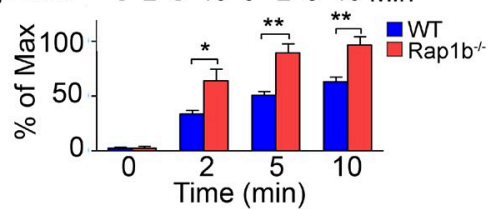

C

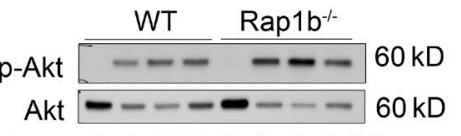

$\begin{array}{llllllllll}\text { fMLP } & 0 & 1 & 2 & 5 & 0 & 1 & 2 & 5 & \text { Min }\end{array}$

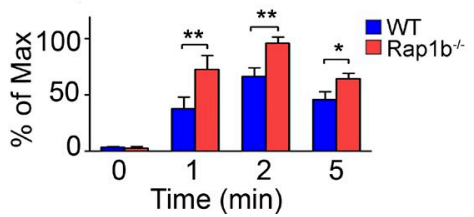

D

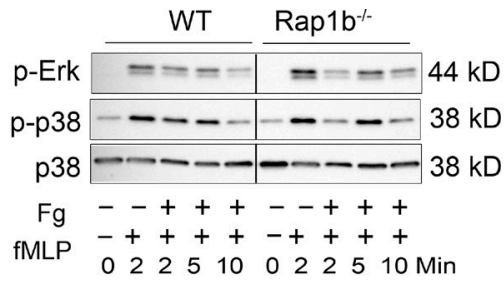

E

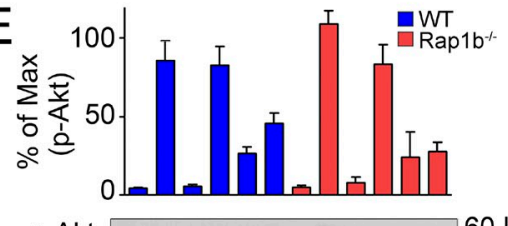

p-Akt - - - -

Akt

p-p38

p38 -

p-Erk

Erk - - - 44 kD

Actin -

fMLP -+++++-+++++

MK-2206 - - +- - - - + - -

Rapamycin - - + + - - - + - -

Ly294002 - - - + - - - - +

PP2

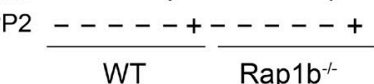

Figure 7. Rap1b negatively regulates PI3K-Akt signaling. (A) Immunostaining analysis of PIP3 in WT and Rap16 $1 b^{-1-}$ neutrophils that were stimulated with FMLP and plated on fibrinogen-coated surface. Bar, $10 \mu \mathrm{m}$. Fluorescence intensities were measured using Openlab software. Mean \pm SD; $n=3$ independent experiments. (B) Kinetics of Phospho-Akt (Ser473) in WT and Rap1b-1- neutrophils using immunoblotting after fMLP stimulation and adhesion on fibrinogen-coated surfaces. Results of Akt phosphorylation expressed as the ratio of phospho-Akt to Akt as densitometry analysis. (C) Immunoblot analysis of p-Akt from WCL of neutrophils that were stimulated with fMLP in suspension. (D) Immunoblotting of $p-p 38$ and p-Erk from WT and Rap $1 b^{-1-}$ neutrophils that were stimulated with $\mathrm{AMLP}$ and plated on fibrinogencoated plates. (E) WT and Rap1b ${ }^{-1-}$ neutrophils were pretreated with indicated inhibitors for 20 min and stimulated with fMLP for 2 min. Akt activation was completely inhibited with Akt inhibitor MK2206 (2 $\mu \mathrm{M})$ and, to a substantial level, with PI3K inhibitor

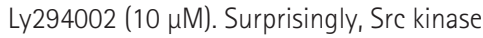
inhibitor PP2 $(10 \mu \mathrm{M})$ also inhibited Akt activation to a substantial level. Furthermore, rapamycin, an inhibitor of mTOR complex 1 failed to inhibit p-Akt. Although p-p38 and $p$-Erk were remained unchanged with these inhibitors, suggested specificity of p-Akt pathway. Blots are representative of three independent experiments (B-E). Densitometry analysis is cumulative of three experiments.

Mean $\pm S D ;{ }^{*}, P<0.05 ;{ }^{*}, P<0.01$, using unpaired Student's $t$ test. significantly defective in CD11 $\mathrm{b}^{-/-}$neutrophils in response to adhesion and $\mathrm{fMLP}$ stimulation (Fig. 9 B). Conversely,Akt phosphorylation was strongly induced in WT cells upon CD11b cross-linking, which enforces CD11b activation (Fig. 9 C; Zhang et al., 2006; Kumar et al., 2012). Interestingly, CD11b crosslinking further increased $\mathrm{p}-\mathrm{Akt}$ in $\mathrm{Rap} 1 \mathrm{~b}^{-/-}$neutrophils (Fig. 9 C), and did not change their abnormal F-actin protrusions (Fig. 9 D), whereas a blocking monoclonal antibody to CD11b reduced p-Akt in Rap1b ${ }^{-1-}$ to WT levels (Fig. 9 E). Hence, Rap1b dampens CD11b-induced Akt activation. This effect seems important for efficient transmigration because matrix degradation reverted to WT levels in Rap $1 \mathrm{~b}^{-1-}$ neutrophils treated with CD11b blocking Ab (Fig. 9 F). Finally, we confirmed that transmigration is CD11b-dependent because CD $11 b^{-/-}$neutrophils exhibited defective transmigration (unpublished data; Phillipson et al., 2006; Zhang et al., 2006). Adoptive transfer of neutrophils further supported impaired

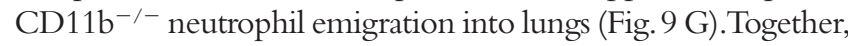
these results suggest that Rap1b acts downstream of CD $11 \mathrm{~b}$ to limit CD11b-induced Akt activation.

\section{Rap1b regulates Akt activity via the phosphatase SHP-1}

Because Rap1b is a GTPase, its effect on Akt activity is likely to be indirect and involve a phosphatase. The nontyrosine receptor SRC-homology region 2 domain-containing phosphatase-1 (SHP-1, also called PTPN6) is an important negative regulator of PI3K-Akt and Src signaling that associates with neutrophil DRMs (Zhang et al., 2005). It is activated by phosphorylation on tyrosine (Y536) residue (Tsui et al., 2006). AMLP-induced total tyrosine phosphorylation of SHP-1 was lower in Rap $1 b^{-/-}$ neutrophils than in WT cells (Fig. $10 \mathrm{~A}$ ), as was its association to DRMs in response to fMLP and fibrinogen (Fig. $10 \mathrm{~B}$ ). Further, SHP-1 redistributed preferentially to the uropod in WT neutrophils stimulated with AMLP and on fibrinogen, but not in Rap1b ${ }^{-/-}$neutrophils, which exhibited homogenous SHP-1 distribution (Fig. 10 C). SHP-2 distribution was unchanged in Rap1 $\mathrm{b}^{-/-}$neutrophils (unpublished data). Importantly, the SHP-1/2 inhibitor NSC-87877 (Nyström et al., 2009) substantially increased matrix degradation (Fig. 10 D) and Akt phosphorylation (Fig. 10 E) in WT cells, supporting the involvement of SHP-1 in neutrophil invasive behavior. 

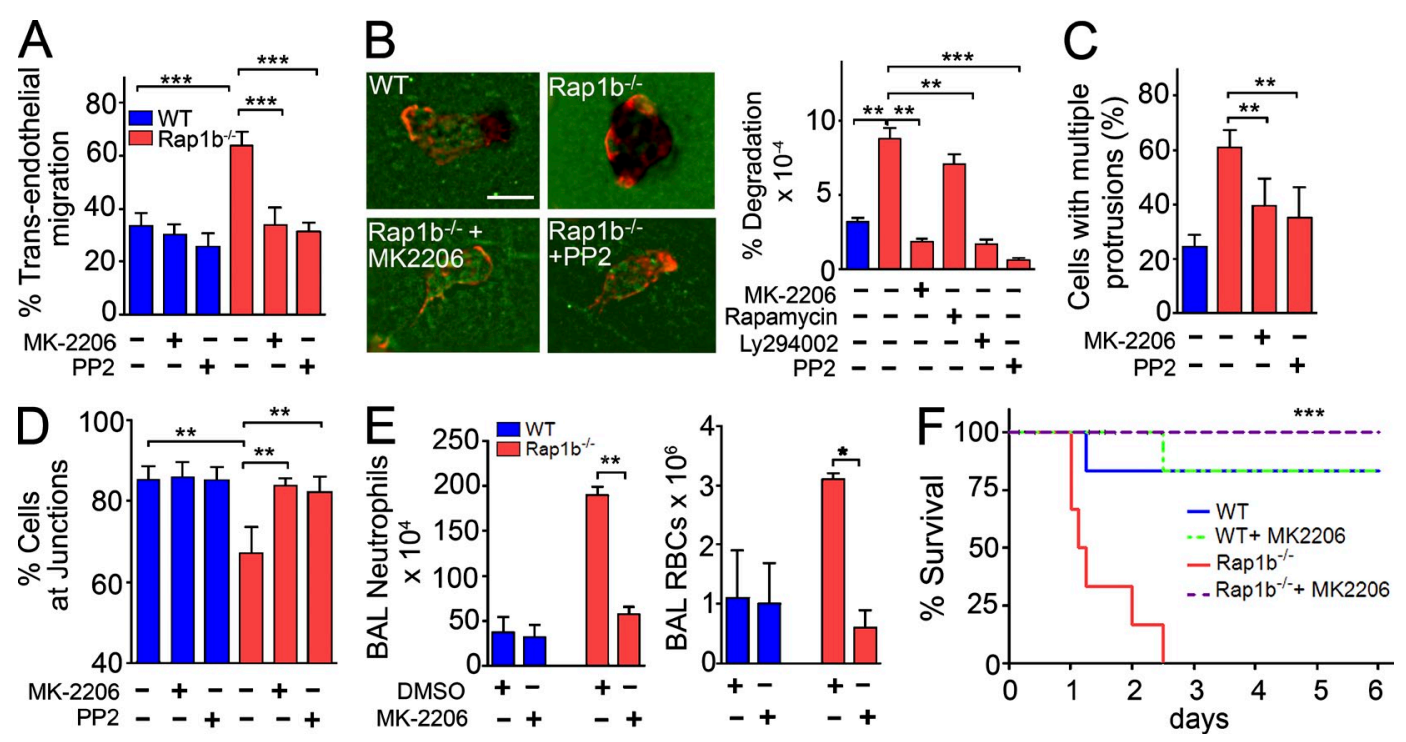

Figure 8. Rap1b negatively regulates neutrophil transcellular migration by limiting PI3K-Akt signaling. (A-D) Effect of Akt inhibitor MK2206 $(2 \mu \mathrm{M})$, Src inhibitor PP2 $(10 \mu \mathrm{M})$, or vehicle control (DMSO) on WT or Rap $1 b^{-1-}$ neutrophil functions. (A) Percentage of neutrophil transendothelial migration in 3D migration model. (B) ECM degradation assessed on Oregon green-labeled gelatin matrix; (left) representative images on (bar, $10 \mu \mathrm{m})$ and (right) bar graph is percentage of matrix degradation. (C) Percentage of cells forming multiple protrusions. (D) Percentage of neutrophils present at junction of activated bEND.3 in 3D migration assay. Mean $\pm S D ; n=3$ independent experiments. ${ }^{* *}, P<0.01 ; * *, P<0.001$; NS, not significant using unpaired Student's $t$ test). ( $E$ and F) Effect of Akt inhibitor on neutrophil infiltration to inflamed lungs and survival of mice; Analysis of BAL at $4 \mathrm{~h}$ for neutrophil infiltration after interstitial LPS $(1.25 \mathrm{mg} / \mathrm{kg})$ challenge in mice $\left(n=4\right.$ mice per group from two independent experiments; mean $\left.\pm S D_{i}^{*}, P<0.05 ;{ }^{*}, P<0.01\right)$. (E) Survival of mice reconstituted with WT or Rap $1 b^{-1-}$ BM ( $n=6$ per group, two independent experiments) injected i.p. with $20 \mathrm{mg} / \mathrm{kg}$ LPS (F), which were pretreated with MK2206 (15 mg/kg) or vehicle control DMSO I h before LPS challenge. ${ }^{* * *}, P=0.00047$ (Rap1b ${ }^{-1-}$ vs. MK2206 treatment, log-rank test).

Therefore, Rap1b limits Akt signaling, likely via SHP-1. Together, these findings reveal Rap1b as a novel suppressor of neutrophil migration by limiting Akt signaling.

\section{DISCUSSION}

Rap1b is an evolutionarily conserved protein of the Ras-like GTPase superfamily (Caron, 2003; Boettner and Van Aelst, 2009; Raaijmakers and Bos, 2009; Katagiri and Kinashi, 2012). The general view has been that Rap1 positively regulates cell adhesion, cell polarity, cell junction formation, and secretion (Caron et al., 2000; Chrzanowska-Wodnicka et al., 2005; Lakshmikanthan et al., 2011; Wittchen et al., 2011; Katagiri and Kinashi, 2012). Rap1 loss often causes cellular migratory and homing defects, as seen in epithelial cells, endothelial cells, and lymphocytes (Caron et al., 2000; Katagiri et al., 2003; Shimonaka et al., 2003; Wittchen et al., 2011). Here, we unexpectedly found that Rap1b is a key suppressor of neutrophil migration and inflammation. Mice reconstituted with Rap1 $b^{-1-}$ hematopoietic cells were more susceptible to LPSinduced endotoxin shock than WT. Rap1b $1 b^{-1-}$ neutrophils exhibited increased emigration into lungs, and increased transmigration in vitro, due to enhanced Akt signaling. Further, this Rap1b pathway appears to selectively limit the formation of invasive protrusions to restrain what may be abnormal transcellular migration in vitro. Our work uncovers a novel functional role for Rap1b in immune cells.

Neutrophils are major effector cells of systemic inflammation induced by endotoxin challenge, illustrated by the fact that neutrophil depletion protects from LPS-induced toxicity (Hewett et al., 1992; Abraham et al., 2000). In general, tissue toxicity results from the uncontrolled accumulation of neutrophils into tissues and their subsequent activation. Neutrophils possess numerous granules that contain a large number of cytotoxic molecules, including numerous proteases, cytokines, elastase, myeloperoxidase and metalloproteinases. Neutrophil activation in tissue triggers neutrophil degranulation and release of these cytotoxic molecules into the extracellular space, as well as respiratory burst via the nicotinamide adenine dinucleotide phosphate (NADPH) oxidase complex, which is a cause of tissue damage. In addition, proinflammatory cytokines, such as IL-1 $\beta$, TGF- $\beta$, and TNF- $\alpha$, are locally released, hence further intensifying inflammation (Zemans et al., 2009). The increased death of LPS-challenged Rap $1 b^{-/-}$-reconstituted mice could thus be caused by multiple factors. We found increased $\mathrm{Rap} 1 \mathrm{~b}^{-/-}$ neutrophil emigration into tissues. The passage of large numbers of activated neutrophils can result in damage to the epithelium, in part due to microscopic wounds in the epithelium (Nusrat et al., 1997). Intriguingly, Rap $1 b^{-/-}$neutrophils used (at least in vitro) an uncommon route of migration, i.e., transcellular diapedesis, during which neutrophils directly migrate through individual endothelial cells (Feng et al., 1998; Carman et al., 2007; Carman and Springer, 2008; Sage and Carman, 2009), although it is currently not known whether migrating transcellularly impacts the intensity of tissue damage and inflammation in vivo. However, there may be a discrepancy between the magnitude of the Rap $1 b^{-1-}$ animal death and the increased 

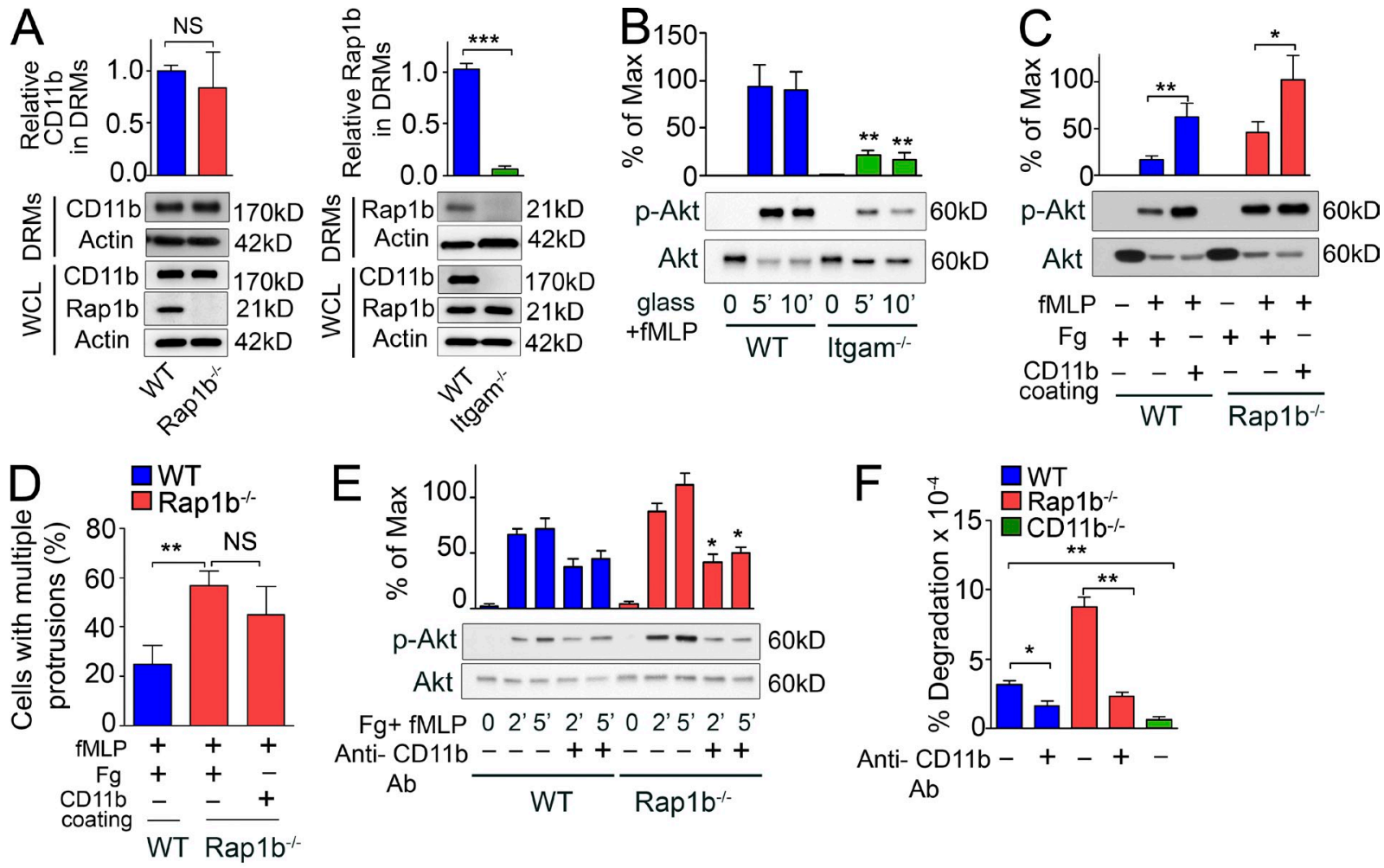

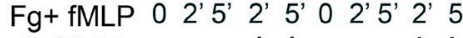

Anti- CD11b - - + + - - + +

$$
\mathrm{Ab}
$$$$
\text { WT }{\operatorname{Rap} 1 \mathrm{~b}^{-1-}}^{-}
$$

$\mathrm{Ab}$
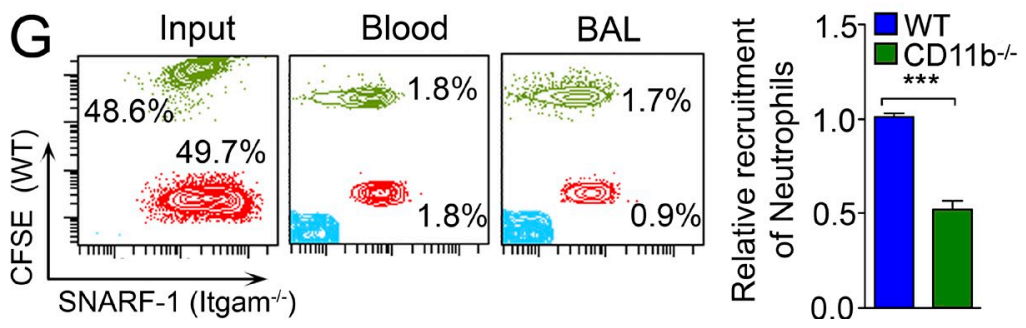

Figure 9. Rap1b negatively regulates PI3K/Akt signaling via CD11b outside-in signaling. (A) Immunoblot analysis of CD11b and Rap 1b in DRM fractions or WCL of Rap1 $1 b^{-1-}$ or CD11 $b^{-1-}$ neutrophils with respective WT controls. (B) Immunoblot analysis of p-Akt in WT and CD11 $b^{-1-}$ neutrophils stimulated on uncoated plates. (C) p-Akt immunoblots analysis of WT and Rap1 $1 b^{-1-}$ neutrophils that were stimulated with fMLP and plated on fibrinogencoated slides or on slides coated with CD11b Ab. (D) Analysis of cells with more than one protrusion using F-actin staining of WT and Rap1b-1neutrophils that were stimulated with fMLP and plated on fibrinogen-coated slides or on slides coated with anti-CD11b. (E) Immunoblot analysis of p-Akt from WT and Rap $1 b^{-1-}$ neutrophils incubated with or without a monoclonal blocking anti-CD11b antibody after stimulation with fMLP and on fibrinogencoated plates. Blots are representative of 3 independent experiments and densitometric analyses are cumulative of 3 experiments (A-C and E). Mean \pm SD. ${ }^{*}, \mathrm{P}<0.05 ;{ }^{* *}, \mathrm{P}<0.01 ;{ }^{* * *}, \mathrm{P}<0.001 ; \mathrm{NS}$, not significant using unpaired Student's $t$ test. (F) Matrix degradation analysis in CD11 $b^{-1-}$ neutrophils or WT and Rap $1 b^{-1-}$ neutrophils treated with blocking anti-CD11b antibody. Mean $\pm S D, n=3$ independent experiments $\left(D\right.$ and F). ${ }^{*}, P<0.05 ;{ }^{* *}, P<0.01 ; N S$, not significant using unpaired Student's $t$ test. (G) Relative recruitment of CSFE and SNARF-1 labeled and adoptively transferred WT and CD11 ${ }^{-1-}$ neutrophils in BAL of LPS challenged mice. Mean $\pm S D ; n=3$ independent experiments. ${ }^{* *}, P<0.001$ (unpaired Student's $t$ test).

neutrophil tissue infiltration, thus suggesting the involvement of additional mechanisms. Increased release of metalloproteinases of Rap $1 b^{-/-}$neutrophils may directly contribute to the high mortality of Rap $1 b^{-/-}$mice due to their tissue matrix degradation activity (Plitas et al., 2003). Because metalloproteinases are released by degranulation, it is possible that $\mathrm{Rap}_{1 \mathrm{~b}}^{-/-}$ neutrophils additionally release numerous cytotoxic agents, including elastase, defensins, leukotriene B4. Other Rap1 b $^{-/-}$ hematopoietic cells, such as macrophages, could also secrete inflammatory mediators, e.g., TNF, IL-1 $\beta$, and IL-6. These molecules play key roles in the pathogenesis of organ damage
(Zemans et al., 2009). For instance, in animal models, elastase administration causes lung injury and elastase inhibition has a protective effect on lung injury (Delacourt et al., 2002; Tremblay et al., 2002). The mechanism by which elastase causes tissue injury could be caused by basement membrane degradation, increased epithelial permeability, or epithelial ulcerations. Defensins are another major component of neutrophil granules and have been shown to cause endothelial injury (Okrent et al., 1990). TNF is a key component of the pathogenesis of inflammation by increasing endothelial cell permeability (Hamacher et al., 2002; Petrache et al., 2003). Overall these 

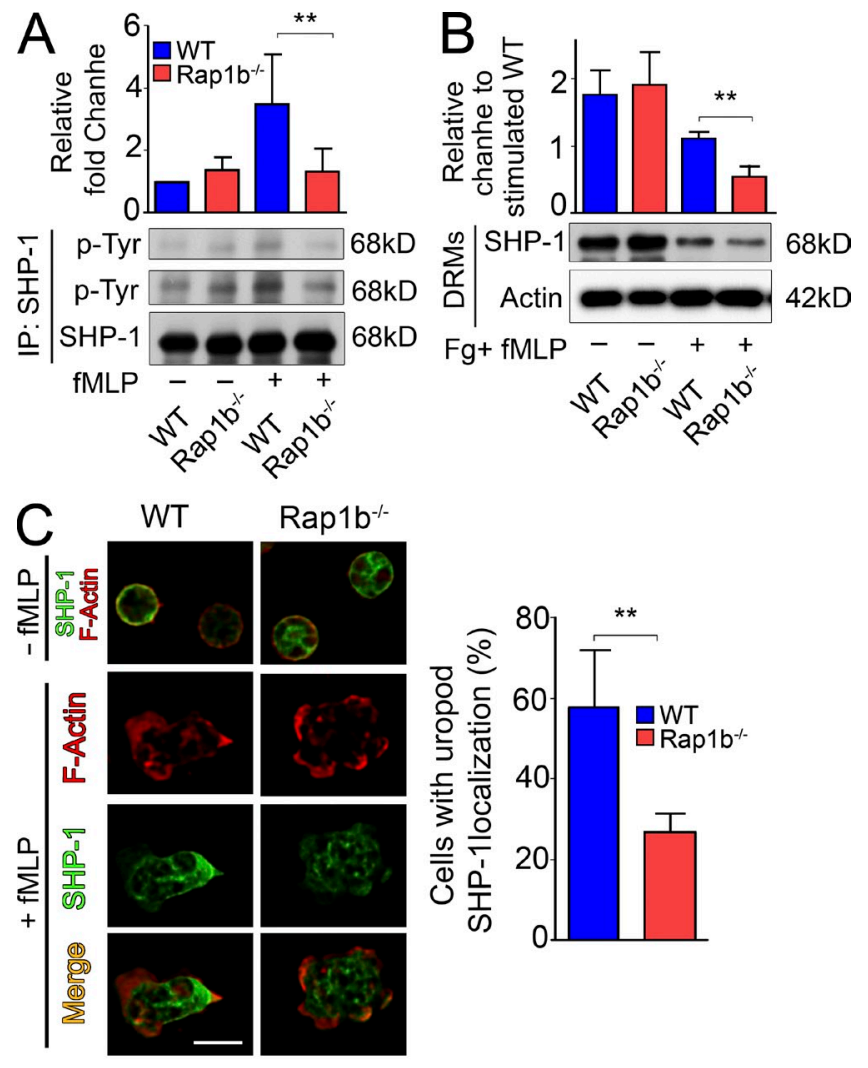
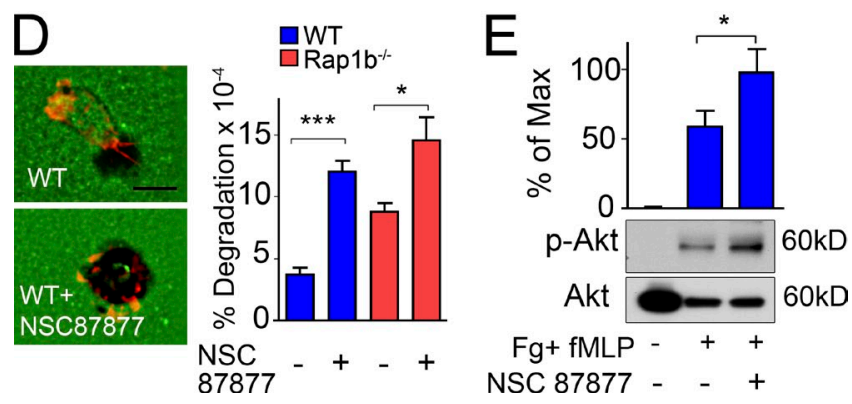

Figure 10. Rap1b regulates ECM degradation via SHP-1. (A) Immunoblot analysis of SHP-1 activation; WCL from WT and Rap $1 b^{-1-}$ neutrophils with or without stimulation were processed for immunoprecipitation with SHP-1 antibody. Blots were first probed with anti-phospho-tyrosine ( $p$-Tyr) antibody followed by SHP-1 antibody. (B) Immunoblot analysis of SHP-1 association to DRM fractions of WT and Rap $1 b^{-1-}$ neutrophils with or without stimulation that were probed with SHP-1 and $\beta$-actin antibodies. (C) Immunofluorescence analysis of SHP-1 and F-actin in WT and Rap $1 b^{-1-}$ neutrophils in resting condition or upon stimulation with $\mathrm{AMLP}$ and plating on Fg. Bar, $10 \mu \mathrm{m}$. Histogram represents percentage of cells with SHP-1 enriched at the uropod (mean $\pm \mathrm{SD} ; n=3$ independent experiment; ${ }^{* *}, P<0.01$; using unpaired Student's $t$ test). (D) Effect of SHP-1/2 inhibitor NSC87877 on matrix degradation. Bar, $10 \mu \mathrm{m}$. Mean \pm SD. $n=3$ independent experiment. $\left.{ }^{*}, \mathrm{P}<0.05 i^{* * *}, \mathrm{P}<0.001\right)$. (E) p-Akt level of WT neutrophils that were pretreated with NSC87877 $(20 \mu \mathrm{M})$ for $20 \mathrm{~min}$. Blots are representative of 3 independent experiments and densitometric analysis are cumulative of 3 experiments $(A, B$, and $E)$. Mean \pm SD. ${ }^{*}, \mathrm{P}<0.05 ;{ }^{*}, \mathrm{P}<0.01$; unpaired Student's $t$ test. insults enhance tissue degradation and permeability that, in the case of the lungs, can lead to lethal edema. Hence, the possible secretion of such factors by Rap $1 b^{-/-}$hematopoietic cells would increase LPS-driven tissue toxicity and animal death. Finally, platelet-neutrophil interaction via CD11b is key to vascular injury (Hidalgo et al., 2009). As Rap1b is a crucial regulator of platelet functions (Lakshmikanthan et al., 2011), defective functions and/or interaction of $\mathrm{Rap} 1 \mathrm{~b}^{-/-}$platelets with neutrophils may also contribute to the increased mortality of Rap $1 b^{-/-}$mice. These possibilities will be interesting to investigate in the future.

Akt signaling appears to mediate the effect of Rap1b deletion on neutrophil functions. The mechanism by which Rap1b limits Akt signaling is unprecedented. Rap1b is known to positively regulate ERK/MAPK and $\mathrm{p} 38^{\mathrm{MAPK}}$ activities through the assembly of IQGAP-mediated signalosome (Awasthi et al., 2010). Rap1b can be activated downstream of PI3K and regulate Cdc42-mediated polarity (Schwamborn and Püschel, 2004). We found no clear evidence of adhesion defects in $\mathrm{Rap}_{1 \mathrm{~b}^{-/-}}$neutrophils. Instead, Rap1b negatively regulates PI3K-Akt signaling pathways in response to both GPCR and outside-in CD11b signaling. Rap1b can be recruited to the triton-insoluble plasma membrane domains by CD11b and, in turn, limits CD11b-induced PI3K-Akt signaling. Rap1b itself is not acting between CD11b and PI3K-Akt, as CD11b cross-linking can enhance Akt phosphorylation in Rap1b $\mathrm{b}^{-/-}$ neutrophils. Instead, Rap $1 \mathrm{~b}$ acts as a counterpart regulatory pathway to limit ligand-induced Akt activation. Because

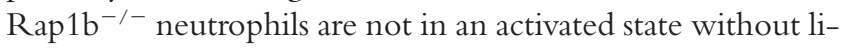
gand stimulation, Rap1b integrates GPCR and integrin signaling to limit excessive ligand-induced activation.

Rap1b, like Ras-related small GTPases, functions though activation of effector kinase proteins (Raaijmakers and Bos, 2009). The elevated PI3k-Akt signals in Rap1b ${ }^{-/-}$neutrophils likely results from failure to activate a negative regulator. We provide evidence that Rap1b may act through the nonreceptor protein-tyrosine phosphatase SHP-1.SHP-1 is a negative regulator of innate immune cell functions by down-modulating signaling pathways, including Src and Akt signaling (Tsui et al., 2006). Neutrophils from mice with genetic deletion of shp-1 or with null mutations in Ptpn6, which encodes SHP-1, have increased actin polymerization, and chemotaxis (Zhang et al., 2005). Thus, impaired SHP-1 activity in Rap1b ${ }^{-/-}$neutrophils may maximize Akt signaling. SHP-1 is classically recruited to the plasma membrane by immunoreceptor tyrosine-based inhibition motifs (ITIMs) bearing receptors, including Siglec-E, PIR-B, or Ly49d (Zhang et al., 2005; Sasawatari et al., 2010; McMillan et al., 2013). Loss of functions of such receptors causes increased neutrophil migration and inflammation (Zhang et al., 2005; Sasawatari et al., 2010; McMillan et al., 2013). It would be interesting to investigate possible cross talk between Rap1b and ITIMs bearing receptors in SHP-1 regulation and transcellular migration.

These findings raise an interesting question about what triggers a transcellular mode of migration over paracellular diapedesis. The local vascular environment seems important. 
Carman and Springer suggested that cells take the path of least resistance. During cell locomotion, podosome-like protrusions would sense endothelial cells for area of least resistance at which cells can extend longer invadopodia-like structures triggering transcellular migration (Carman et al., 2007; Carman and Springer, 2008). As such, neutrophils use transcellular diapedesis to migrate through the blood-brain barrier, where endothelial junctions are particularly tight (von Wedel-Parlow et al., 2011). In addition, endothelial cells enriched in ICAM tend to promote the transcellular route (Yang et al., 2005). However, this cannot be the only mechanism, as transcellular migration can also occur on low-resistant endothelial cells. In this case, the level of neutrophil activation and subsequent activation of specific intracellular signals may be an important determinant factor. The fact that intradermal injection of fMLP stimulates transcellular migration in vivo (Feng et al., 1998), or that direct activation by fMLP of neutrophils plated on endothelial cells increases transcellular migration events in vitro (Mamdouh et al., 2009) support this idea that transcellular migration can be promoted when neutrophils are highly activated. Because the strength of stimuli-induced intracellular signals can trigger various cellular responses, it is possible that high neutrophil activation may promote invasive actin protrusions to form in tissue environment with loose endothelial junctions, and increase their ability to migrate transcellularly. Our findings suggest that neutrophil invasive protrusions and transcellular migration in vitro depends on high Akt signal intensity. Rap $1 b^{-/-}$neutrophils seem to become more invasive with increased actin polymerization, invadopodia and MMP release in vitro, in a manner dependent on high Akt signals. Inhibition of Akt signaling in these cells blocks transcellular but not paracellular migration in vitro. Hence, Akt signal robustness seems to trigger a neutrophil response that will specifically determine transcellular migration in vitro. Akt signal strength may promote MMP release and convert noninvasive lamellipodial protrusions into invasive podosome structures. Because transcellular migration requires the formation of a transcellular channel and membrane fusion of the endothelial lateral border recycling compartment (LBRC; Mamdouh et al., 2009), Akt-driven invasive protrusions may send signals to endothelial cells to recruit the LBRC and initiate the formation of the transcellular pore away from the junction. Our findings strongly suggest that Rap1b loss directly increased the ability of neutrophils to exploit the transcellular pathway by enhancing intracellular signaling intensity. Rap1b-Akt signaling pathway may operate as a switch signal that controls the occurrence of invasive protrusions to balance paracellular and transcellular migration, at least in vitro.

ALI is triggered by excessive neutrophil infiltration of the airway wall. Neutrophil emigration into the lung takes place via the small capillaries, in contrast to the systemic circulation where neutrophils enter tissue via postcapillary venules. The lumen of the pulmonary capillary is extremely narrow $(2-15$ $\mu \mathrm{m})$ preventing rolling along the endothelium (Brown et al., 2006; Grommes and Soehnlein, 2011); thus, neutrophil emigration in the lungs is largely integrin dependent (Brown et al.,
2006). Hence, Rap1b regulatory signaling in immune cells has far reaching importance for inflammatory processes. Such understanding may help in designing effective therapeutics for treating acute and chronic inflammatory diseases.

\section{MATERIALS AND METHODS}

Antibodies and reagents. Antibodies against $\alpha \mathrm{L} / \mathrm{LFA}-1$ (2D7), $\alpha \mathrm{M} / \mathrm{Mac1}$ / CD11b (M1/70), $\beta 2$ (C17/16), and Rap1 were obtained from BD. Human anti-ICAM-1 (HA58) and $\beta 1$ (eBioHmb1-1) were obtained from eBioscience. Phospho -Akt (Ser473), Akt, p-p38, p38, p-Erk, Erk, Rap1b, and anti-VEcadherin (clone 55-7H1) were purchased from Cell Signaling Technology. Anti-SHP-1 antibody was obtained from Santa Cruz Biotechnology, Inc. Rhodamine-labeled phalloidin, $\operatorname{IgG}$ conjugated to Alexa Fluor 488, Alexa Fluor 594, Alexa 6Fluor 47, or Cy5 were obtained from Invitrogen. AntiPIP3 antibody and PTEN inhibitor SF-1670 were from Echelon Biosciences. Antibody used for immunoblotting of CD11b was from Abcam, Src-inhibitor PP2, SHP-1/2 inhibitor NSC87877, and serine-protease inhibitor DFP were obtained from EMD Millipore. Akt-inhibitor MK2206 was obtained from Selleckchem. Rac inhibitor NSC23766 was a gift from Y. Zheng (Cincinnati Children's Hospital Medical Center, Cincinnati, USA). Anti- $\beta$-actin antibody and PI3K inhibitor Ly294002 were obtained from Sigma-Aldrich.

Mice strains. The Rap1b-null mice (Rap16 ${ }^{-/-}$; C57BL/6 background $n>10$ generations) were described previously (Chrzanowska-Wodnicka et al., 2005). CD11b-deficient animals (Itgam ${ }^{\left.\operatorname{tm} 1 M_{Y d}\right)}$ ) were purchased from The Jackson Laboratory. All experimental procedures and animal protocol were approved by the Cincinnati Children's Institutional Animal Care and Use Committee in accordance with AAALAC accreditation standards.

LPS-induced lung inflammation. For BAL and histology, the mice were challenged with $1.25 \mathrm{mg} / \mathrm{kg}$ LPS from Escherichia coli O111:B4 by intratracheal instillation after ketamine and xylazine anesthesia. BALs and lung histology were performed as previously described (Filippi et al., 2007; Kumar et al., 2012). For survival curve analysis, $20 \mathrm{mg} / \mathrm{kg}$ LPS was injected i.p. in $300 \mu \mathrm{l}$ saline solution. When indicated, mice were pretreated with MK2206 $(15 \mathrm{mg} / \mathrm{kg})$ or vehicle control DMSO one hour before LPS challenge. Mice were followed for $6 \mathrm{~d}$, and then, survived mice were sacrificed.

Neutrophil migration in vitro. Neutrophil isolation was previously described (Szczur et al., 2009; Kumar et al., 2012). Chemokinesis or random migration was analyzed by using chemoattractant in both well of Boyden system and Transwell plates, whereas chemotaxis was recorded by adding chemoattractant in the lower well as described previously (Szczur et al., 2009). Time lapse video microscopy was performed in a Zigmond chamber (Neuro Probe) on a surface coated with fibrinogen in gradient of $10 \mu \mathrm{M}$ fMLP as previously described (Szczur et al., 2009). Migration was recorded with an Axiovert 200 microscope (Carl Zeiss) at $10 \times / 0.3 \mathrm{NA}$ objective, equipped with ORCA-ER camera (Hamamatsu) and driven by Image software (National Institutes of Health). Analysis of cell migration, speed (Sp,) and straightness (St; distance from origin to total distance covered) of migration was performed in the motile population that had moved $>20 \mu \mathrm{m}$ using Image software. Quantifications were performed on at least 30 cells from individual experiment/video and from 3 independent experiments.

Neutrophil adoptive transfer. Neutrophils isolated from WT or Rap1bko bone marrow were labeled with CFSE (green; $2.5 \mu \mathrm{M}$; Invitrogen) and chloromethyl SNARF-1 acetate (red; $5 \mu \mathrm{M}$; Invitrogen) or vice-versa, at $37^{\circ} \mathrm{C}$ for $10 \mathrm{~min}$. The labeled cells were mixed at a $1: 1$ ratio and transfer into WT recipient though i.v. injection at the time of LPS challenge. The relative amounts of labeled neutrophils of the mixed population recovered after transfer in the blood and in BALF were analyzed by flow cytometer (FACSCanto; BD; Kumar et al., 2012). Relative neutrophil recruitment was calculated as the ratio of $\mathrm{Rap} 1 \mathrm{~b}^{-/-}$relative to WT neutrophils. 
Immunofluorescence. Neutrophils were stimulated with AMLP in HBSS containing $0.1 \% \mathrm{BSA}, 1 \mathrm{mM} \mathrm{Ca}^{2+}, 1 \mathrm{mM} \mathrm{Mg}^{2+}$, and on fibrinogen-coated slides or anti-CD $11 \mathrm{~b}$-coated slides, for $0-10 \mathrm{~min}$ at $37^{\circ} \mathrm{C}$. The anti-CD $11 \mathrm{~b}-$ coated slides were used for antibody-mediated cross-linking experiments to enforce CD11b activation (Kumar et al., 2012). All samples were fixed with $2 \% \mathrm{PFA}$ at room temperature, until specified. To examine the intracellular distribution of various proteins, the cells were permeabilized with $0.1 \%$ Triton X-100 and stained for the intracellular protein. For PIP3 staining, cells were fixed with $4 \%$ PFA and permeabilized with $0.1 \%$ saponin for $10 \mathrm{~min}$ and stained with PIP3 and appropriate fluorescently labeled secondary in the presence of $0.05 \%$ saponin. Fluorescence images or $\mathrm{Z}$ series of fluorescence images were captured using a Leica DMI6000 fluorescence microscope at $63 \times / 1.3$ NA objective, with ORCA-ER C4742-95 camera (Hamamatsu) driven by Openlab software (Szczur et al., 2009; Kumar et al., 2012). Z series were analyzed by deconvolution using Volocity (Improvision). Fluorescence intensity quantifications were performed in Openlab, Volocity, and Image softwares (Szczur et al., 2009) on cells that show increased spreading and positive F-actin polymerization in response to the stimulation. Quantifications shown in the study are represented as mean $\pm \mathrm{SD}$ and are from at least 30 cells per experiment and representative of at least 3 independent experiments.

Crawling/transendothelial migration assay. Confluent monolayers of endothelium cells (HUVECs and bEND.3 murine brain endothelial cells) were grown on hydrated collagen gels in DMEM (American Type Culture Collection [ATCC]) plus 20\% FBS, as in previous works (Muller, 2011; Schenkel et al., 2004). Endothelium monolayers were incubated with or without LPS $(2 \mu \mathrm{g} / \mathrm{ml})$ for $4-6 \mathrm{~h}$ in a $\mathrm{CO}_{2}$ incubator for activation. Neutrophils were washed in HBSS plus $0.1 \%$ bovine serum albumin, were resuspended at a density of $2 \times 10^{6}$ cells $/ \mathrm{ml}$ in DMEM plus $0.5 \% \mathrm{FBS}$ for crawling and transendothelial migration. Neutrophils were incubated on activated endothelial cells for 15-30 min, after incubation monolayers were washed twice with PBS for removal of nonadherent cells and the remaining adherent and transmigrated cells were fixed in place on the endothelial monolayer by overnight incubation in $2.5 \%$ glutaraldehyde in $0.1 \mathrm{M}$ sodium cacodylate buffer at $\mathrm{pH}$ 7.4. Total number of cells per high-power field was determined by counting cells both on the apical surface and in the collagen. For quantification of transendothelial migration, neutrophils that were below endothelial monolayers were counted and divided by the total number of cells per highpower field of bright-field microscope. For identification of neutrophil position on endothelial monolayer, endothelial cell junctions were stained with silver staining. Endothelial monolayers with neutrophils were washed once in PBS and twice in 5\% glucose, and then stained with $0.5 \%$ silver nitrate $/ 1 \%$ ammonium bromide/3\% cobalt bromide before fixation in 5\% phosphate buffered formalin. The cells were examined by microscope for quantification of neutrophil position on endothelial cells. Where indicated, neutrophils were pretreated with the Src-inhibitor PP2 $(10 \mu \mathrm{M})$, Akt-inhibitor MK2206 $(2 \mu \mathrm{M})$, or an equal dilution of vehicle (DMSO) for $30 \mathrm{~min}$.

Quantification of transcellular and paracellular diapedesis. Endothelial bEND. 3 and HUVEC monolayers were grown on $0.2 \%$ gelatin-coated 30-mm glass bottom discs in DMEM medium (ATCC) with 20\% FBS and were not activated or activated for 4-6 h with LPS $(2 \mu \mathrm{g} / \mathrm{ml})$ before use. Endothelial cells were washed five times before addition of neutrophils with DMEM supplemented with $20 \mathrm{mM}$ Hepes (pH 7.2) and 0.5\% FBS. $2 \times 10^{5}$ neutrophils were washed and suspended in the same buffer and incubated on endothelial monolayers at $37^{\circ} \mathrm{C}$ in a $\mathrm{CO}_{2}$ incubator for the $10-12 \mathrm{~min}$ to capture the transmigration events. The medium was gently removed and cells were fixed with $2 \%$ paraformaldehyde (prewarmed at $37^{\circ} \mathrm{C}$ a few minutes before) at room temperature for $15 \mathrm{~min}$. The paracellular and transcellular route of TEM was identified by fluorescence staining of mouse or human, respectively,VE-cadherin, ICAM-1, Gr-1, and F-actin. ICAM-1 was stained to visualize the endothelial cell morphology as well as the membrane remodeling in response to neutrophil adhesion and transmigration (Carman et al., 2003; Carman and Springer, 2004). VE-cadherin, Gr-1, and F-actin were used to identify endothelial junction, neutrophils and actin channel formed during diapedesis. After fixation, cells were permeabilized with $0.1 \%$ saponin for $5 \mathrm{~min}$. Subsequently, cells were incubated with primary antibody for $45 \mathrm{~min}$ and washed and incubated with secondary fluorescence antibodies for $45 \mathrm{~min}$ in the presence of $0.05 \%$ saponin. After washing, stained monolayers were mounted with slow-fade containing DAPI to visualize nuclei.

Image acquisition and processing. Confocal imaging was performed with Nikon A1R Confocal Laser Scanning Microscope (Nikon) using a 40x and $60 \mathrm{x}$ water objective. For serial z-stacks, the section thickness was between 0.2 and $0.4 \mu \mathrm{m}$. Image processing, including background subtraction, threedimensional reconstruction, tiles view, and projection of Z-stacks were performed with NIS-elements image analysis software version 4.01. Images were then exported to Photoshop software for preparation of final images. For identification of neutrophils with transmigratory cups that were enriched with ICAM- 1 microvilli, large images $(4 \times 4$ fields) were captured with an open pinhole on Nikon A1R Confocal Laser Scanning Microscope using $60 \times$ water objective with $15 \%$ overlap. Percentages of WT and Rap $1 b^{-/-}$neutrophils with transmigratory cups were calculated from 4 independent experiments.

Transmission electron microscopy. Endothelial (HUVEC) monolayers grown on gelatin-coated ALCAR membranes, with or without LPS activation, were incubated with neutrophils for $10 \mathrm{~min}$ at $37^{\circ} \mathrm{C}$. Cells were fixed with $2.5 \%$ glutaraldehyde and $3 \%$ paraformaldehyde in $0.1 \mathrm{M}$ sodium cacodylate buffer ( $\mathrm{pH}$ 7.4) for $2 \mathrm{~h}$, postfixed in $1.5 \%$ buffered $\mathrm{OsO}_{4}$ for $1 \mathrm{~h}$, dehydrated in a series of graded alcohols, and embedded in Epon 812. ALCAR membranes were then separated from the endothelial monolayer. Thin sections of $100 \mathrm{~nm}$ were cut perpendicular to the monolayer or long axis of the block (and to the plane of the monolayer) and collected on copper single-slot $(1 \times 2 \mathrm{~mm})$ grids coated with Formvar and stained with uranyl acetate. Cells were visualized with a Philips CM-10 electron microscope at $80 \mathrm{kV}$ (Shulman et al., 2009). Quantification of length of microvillus protrusions and invasive protrusions were performed in ImageJ software from at least 30 cells from 3 experiments with $>120$ protrusions.

F-actin quantitation by flow cytometry. Flow cytometry was used to measure the relative amount of filamentous actin per neutrophil, as reported previously (Roberts et al., 1999; Kumar et al., 2012). Neutrophils were stimulated with fMLP in HBSS containing $0.1 \% \mathrm{BSA}, 1 \mathrm{mM} \mathrm{Ca}^{2+}$, and $1 \mathrm{mM}$ $\mathrm{Mg}^{2+}$ at $37^{\circ} \mathrm{C}$. Cells were fixed with $4 \%$ paraformaldehyde, permeabilized with $0.1 \%$ Triton X-100, and stained with rhodamine/phalloidin (1:40). The results are reported as arbitrary units of mean cellular fluorescence (AU). To normalize data between experiments, the mean cellular fluorescence of untreated wild-type neutrophils was arbitrarily assigned a value of $100 \%$.

ECM degradation assay. Matrix degradation was performed by using fluorescent gelatin (Oregon Green; Molecular Probes) as previously described (Artym et al., 2006). To assess the ability of cells to degrade matrix, $5 \times 10^{4}$ WT and Rap $1 b^{-1-}$ neutrophils were stimulated on coverslips coated with fluorescent gelatin matrix for $10 \mathrm{~min}$ at $37^{\circ} \mathrm{C}$. Cells were then fixed with $4 \%$ paraformaldehyde for $15 \mathrm{~min}$ at room temperature and followed by permeabilization with $0.1 \%$ Triton X-100 in PBS. Cells were then washed with PBS, labeled with rhodamine/phalloidin for F-actin staining. Foci of degraded matrix were identified as dark areas that lack fluorescence and appear as holes in the bright fluorescent gelatin matrix. Number of holes per $20 \times$ field and degraded area were calculated from three to five independent experiments.

Zymography assay. Neutrophils $\left(10^{7}\right.$ cells $\left./ \mathrm{ml}\right)$ were stimulated with $\mathrm{fMLP}$ $(5 \mu \mathrm{M})$ in $\mathrm{HBSS}-0.1 \% \mathrm{BSA}$ for indicated time points at $37^{\circ} \mathrm{C}$. Supernatants were collected after centrifugation at $13,000 \mathrm{rpm}$ for $5 \mathrm{~min}$ at $4^{\circ} \mathrm{C}$. The supernatants $(5 \mu \mathrm{l})$ were mixed with a nonreducing buffer $(40 \%$ glycerol, $1 \mathrm{M}$ Tris- $\mathrm{HCl}, \mathrm{pH} 6.8$, and $8 \%$ SDS) and separated on $7.5 \%$ acrylamide gels containing $0.2 \%$ gelatin. Gels were washed twice for $30 \mathrm{~min}$ with $2.5 \%$ Triton $\mathrm{X}-100$ in buffer $(50 \mathrm{mM}$ Tris- $\mathrm{HCl}, \mathrm{pH} 7.4,100 \mathrm{mM} \mathrm{NaCl}$, and $5 \mathrm{mM}$ $\mathrm{CaCl}_{2}$ ) for removal of SDS and renaturation of MMPs. Gels were incubated overnight in digestion buffer $(50 \mathrm{mM}$ Tris- $\mathrm{HCl}, \mathrm{pH} 7.4,150 \mathrm{mM} \mathrm{NaCl}$, and 
$5 \mathrm{mM} \mathrm{CaCl}_{2}$ ) for digestion of gelatin. The gels were stained with Coomassie blue $0.1 \%$ and destained. Densitometric analysis of clear band at $92 \mathrm{kD}$ that corresponds to gelatinase was performed by using ImageJ software.

Adhesion assay. WT and Rap $1 \mathrm{~b}^{-/-}$neutrophils were resuspended in HBSS buffer containing $0.1 \%$ BSA. Cells were added to the coverslips coated with diverse ligands and stimulated for $5 \mathrm{~min}$ at $37^{\circ} \mathrm{C}$. The assay was stopped by immersing the coverslip in $4 \%$ formaldehyde solution. The adherent cells were counted (the mean number of cells per field of view was calculated from five fields of view) using an Axiovert 200 (Carl Zeiss) with a 40× objective.

Preparation of WCLs and DRM fractions, immunoprecipitation, and Western blotting. To examine protein expression in various cellular domains, neutrophils were either maintained in suspension without stimulation or stimulated with $\mathrm{AMLP}$ in suspension or plated on fibrinogen-coated/antiCD11b-coated plates for specific times, as indicated in the figures. WCL was performed using standard triton-based lysis buffer.Triton insoluble or DRMs were prepared as described before (Kumar et al., 2012). Cell lysates containing equal amounts of protein were separated by SDS-PAGE and probed for p-Akt, Akt, p-p38, p38, p-Erk, ERrk, and Rap1b (all from Cell Signaling Technology, Boston, MA), actin (Sigma-Aldrich), CD11b (Abcam), and Rap1 (BD). For immunoprecipitation, rested or stimulated WT and Rap1b ${ }^{-/-}$neutrophils were lysed in $1 \% \mathrm{NP}-40$ lysis buffer and $500 \mu \mathrm{g}$ protein was subjected to each immunoprecipitation with $2 \mu \mathrm{g}$ anti-SHP-1 antibody, followed by protein $\mathrm{A} / \mathrm{G}$ agarose beads. Blots were probed with anti-phospho-tyrosine $4 \mathrm{G} 10$ antibody, followed by anti-SHP-1 (Santa Cruz Biotechnology, Inc.) antibody.

Measurement of calcium signaling. WT and $\mathrm{Rap} 1 \mathrm{~b}^{-/-}$neutrophils were loaded with Fluo-3 AM $(1 \mu \mathrm{g} / \mathrm{ml})$ for $30 \mathrm{~min}$ at $37^{\circ} \mathrm{C}$ in HBSS. Cells were analyzed by flow cytometry (FACSCanto II) for time kinetics and activated by different concentration of AMLP or Ionomycin. Intracellular calcium release kinetics were analyzed using Flowjo software (Tree Star).

Proteomics analysis of DRMs. Proteomics analysis of WT and Cdc42-/neutrophil DRM fractions was performed using LCMSMS orbitrap according to standard protocol at Ohio State University, Ohio.

Superoxide generation. WT and Rap $1 \mathrm{~b}^{-/-}$neutrophils $\left(1 \times 10^{6}\right)$ in suspension were incubated with H2-DCFDA in accordance with the manufacturer's instructions (Molecular Probes). Cells were then stimulated with 1-10 $\mu \mathrm{M}$ fMLP (Sigma-Aldrich) for $15 \mathrm{~min}$ before FACS analysis for mean fluorescence intensity. Fold change stimulation was calculated by normalization of fMLP-stimulated neutrophils fluorescence intensity to unstimulated control WT cells. For superoxide production under adherent conditions, neutrophils $\left(2 \times 10^{5}\right)$ were incubated with $10 \mu \mathrm{M}$ of advanced luminol derivative L012 (8-amino-5-chloro-7-phenylpyrido [3,4-d] pyridazine-1,4[2H,3H] dione), $10 \mathrm{mU}$ horseradish peroxidase (HRP; Sigma-Aldrich) in HBSS buffer for $10 \mathrm{~min}$ on a fibrinogen-coated 96-well plate (Greiner Bio One). Reactions were started by addition of $30 \mu \mathrm{l}$ of stimuli fMLP $(0.5-10 \mu \mathrm{M})$ or PMA $(20 \mathrm{nM})$. Chemiluminescence was measured at every $5 \mathrm{~s}$ for $20 \mathrm{~min}$ using GloMax-96 Microplate Luminometer (Promega).

Statistics. All the experiments were performed at least three times. An unpaired Student's $t$ test (normally distributed) was performed as statistics using Prism 5 software (GraphPad) for comparison of experimental groups unless specified. For survival curve statistics analysis, Log-rank test was used. Data are mean $\pm \mathrm{SD}$. The p-value of $*, \mathrm{P}<0.05 ; * *, \mathrm{P}<0.01$; and ***, $\mathrm{P}<0.001$ were considered as significant.

Online supplemental material. Video 1 shows migration of Rap $1 b^{-1-}$ neutrophils in gradient of $\mathrm{AMLP}$ and on fibrinogen-coated surface. Video 2 shows migration of WT neutrophil in gradient of AMLP and on fibrinogencoated surface. In both videos, $\mathrm{MLP}$ concentration increases from the left to the right. Online supplemental material is available at http://www.jem.org/ cgi/content/full/jem.20131706/DC1.
We thank W.A. Muller (Northwestern University Feinberg School of Medicine) for critical advice on the 3D TEM and crawling assay. We thank the proteomics facility at Ohio State University, Ohio for LCMSMS orbitrap proteomics analysis. We thank the mouse core, Jeff Bailey and Victoria Summey, for bone marrow transplantation and the Pathology Research Core for assistance with transmission electron microscopy studies at Cincinnati Children's Hospital Medical Center.

The work was supported by National Institutes of Health (HL090676 to M.-D. Filippi; HL111582 to M. Chrzanowska-Wodnicka,; and R01HL077177, R01HL081111, R01CA173852, and R01CA134777 to R. Kapur).

The authors declare no competing financial interests.

Author contributions: S. Kumar designed and performed experiments, analyzed the data and wrote the paper; J. Xu performed experiments; R. Sani Kumar performed experiments; S. Lakshmikanthan performed experiments; R. Kapur provided key advice in research design and editing the paper; M. Kofron provided key advice in research design, data analysis, and editing the paper; M. Chrzanowska-Wodnicka contributed vital reagents by providing the Rap $1 b$ knock out mouse and provided key advice in research design and data analysis; M.-D. Filippi designed and directed the program research, analyzed data, and wrote and edited the manuscript.

\section{Submitted: 13 August 2013}

Accepted: 1 July 2014

\section{REFERENCES}

Abraham, E., A. Carmody, R. Shenkar, and J. Arcaroli. 2000. Neutrophils as early immunologic effectors in hemorrhage- or endotoxemia-induced acute lung injury. Am. J. Physiol. Lung Cell. Mol. Physiol. 279:L1137-L1145.

Artym, V.V., Y. Zhang, F. Seillier-Moiseiwitsch, K.M. Yamada, and S.C. Mueller. 2006. Dynamic interactions of cortactin and membrane type 1 matrix metalloproteinase at invadopodia: defining the stages of invadopodia formation and function. Cancer Res. 66:3034-3043. http://dx.doi .org/10.1158/0008-5472.CAN-05-2177

Awasthi, A., A. Samarakoon, H. Chu, R. Kamalakannan, L.A. Quilliam, M. Chrzanowska-Wodnicka, G.C. White II, and S. Malarkannan. 2010. Rap1b facilitates NK cell functions via IQGAP1-mediated signalosomes. J. Exp. Med. 207:1923-1938. http://dx.doi.org/10.1084/jem.20100040

Boettner, B., and L. Van Aelst. 2009. Control of cell adhesion dynamics by Rap1 signaling. Curr. Opin. Cell Biol. 21:684-693. http://dx.doi.org/10 .1016/j.ceb.2009.06.004

Brown, K.A., S.D. Brain, J.D. Pearson, J.D. Edgeworth, S.M. Lewis, and D.F. Treacher. 2006. Neutrophils in development of multiple organ failure in sepsis. Lancet. 368:157-169. http://dx.doi.org/10.1016/S0140-6736(06)69005-3

Buccione, R., J.D. Orth, and M.A. McNiven. 2004. Foot and mouth: podosomes, invadopodia and circular dorsal ruffles. Nat. Rev. Mol. Cell Biol. 5:647-657. http://dx.doi.org/10.1038/nrm1436

Carbo, C., D. Duerschmied, T. Goerge, H. Hattori, J. Sakai, S.M. Cifuni, G.C. White II, M. Chrzanowska-Wodnicka, H.R. Luo, and D.D. Wagner. 2010 Integrin-independent role of CalDAG-GEFI in neutrophil chemotaxis. J. Leukoc. Biol. 88:313-319. http://dx.doi.org/10.1189/jlb.0110049

Carman, C.V., and T.A. Springer. 2004.A transmigratory cup in leukocyte diapedesis both through individual vascular endothelial cells and between them J. Cell Biol. 167:377-388. http://dx.doi.org/10.1083/jcb.200404129

Carman, C.V., and T.A. Springer. 2008. Trans-cellular migration: cell-cell contacts get intimate. Curr. Opin. Cell Biol. 20:533-540. http://dx.doi.org/ 10.1016/j.ceb.2008.05.007

Carman, C.V., C.D. Jun, A. Salas, and T.A. Springer. 2003. Endothelial cells proactively form microvilli-like membrane projections upon intercellular adhesion molecule 1 engagement of leukocyte LFA-1.J. Immunol. 171:6135-6144. http://dx.doi.org/10.4049/jimmunol.171.11.6135

Carman, C.V., P.T. Sage, T.E. Sciuto, M.A. de la Fuente, R.S. Geha, H.D. Ochs, H.F. Dvorak, A.M. Dvorak, and T.A. Springer. 2007. Transcellular diapedesis is initiated by invasive podosomes. Immunity. 26:784-797. http://dx.doi.org/10.1016/j.immuni.2007.04.015

Caron, E. 2003. Cellular functions of the Rap1 GTP-binding protein: a pattern emerges. J. Cell Sci. 116:435-440. http://dx.doi.org/10.1242/jcs.00238

Caron, E., A.J. Self, and A. Hall. 2000. The GTPase Rap1 controls functional activation of macrophage integrin alphaMbeta2 by LPS and other inflammatory mediators. Curr. Biol. 10:974-978. http://dx.doi.org/10 .1016/S0960-9822(00)00641-2 
Chin,Y.R., and A. Toker. 2009. Function of Akt/PKB signaling to cell motility, invasion and the tumor stroma in cancer. Cell. Signal. 21:470-476. http://dx.doi.org/10.1016/j.cellsig.2008.11.015

Chrzanowska-Wodnicka, M., S.S. Smyth, S.M. Schoenwaelder, T.H. Fischer, and G.C. White II. 2005. Rap1b is required for normal platelet function and hemostasis in mice. J. Clin. Invest. 115:680-687. http://dx.doi.org/ 10.1172/JCI22973

Cicchetti, G., P.G. Allen, and M. Glogauer. 2002. Chemotactic signaling pathways in neutrophils: from receptor to actin assembly. Crit. Rev. Oral Biol. Med. 13:220-228. http://dx.doi.org/10.1177/154411130201300302

Delacourt, C., S. Hérigault, C. Delclaux, A. Poncin, M. Levame, A. Harf, F Saudubray, and C. Lafuma. 2002. Protection against acute lung injury by intravenous or intratracheal pretreatment with EPI-HNE-4, a new potent neutrophil elastase inhibitor. Am.J. Respir. Cell Mol. Biol. 26:290297. http://dx.doi.org/10.1165/ajrcmb.26.3.4611

Feng, D., J.A. Nagy, K. Pyne, H.F. Dvorak, and A.M. Dvorak. 1998 Neutrophils emigrate from venules by a transendothelial cell pathway in response to FMLP.J. Exp. Med. 187:903-915.http://dx.doi.org/10.1084/ jem.187.6.903

Filippi, M.D., K. Szczur, C.E. Harris, and P.Y. Berclaz. 2007. Rho GTPase Rac1 is critical for neutrophil migration into the lung. Blood. 109:12571264. http://dx.doi.org/10.1182/blood-2006-04-017731

Gerard, A., R.A. van der Kammen, H. Janssen, S.I. Ellenbroek, and J.G. Collard. 2009. The Rac activator Tiam1 controls efficient T-cell trafficking and route of transendothelial migration. Blood. 113:6138-6147.

Grommes, J., and O. Soehnlein. 2011. Contribution of neutrophils to acute lung injury. Mol. Med. 17:293-307. http://dx.doi.org/10.2119/molmed .2010 .00138

Hamacher, J., R. Lucas, H.R. Lijnen, S. Buschke, Y. Dunant, A. Wendel, G.E. Grau, P.M. Suter, and B. Ricou. 2002. Tumor necrosis factor-alpha and angiostatin are mediators of endothelial cytotoxicity in bronchoalveolar lavages of patients with acute respiratory distress syndrome. Am. J. Respir. Crit. Care Med. 166:651-656. http://dx.doi.org/10.1164/rccm.2109004

Hewett, J.A., A.E. Schultze, S.VanCise, and R.A. Roth. 1992. Neutrophil depletion protects against liver injury from bacterial endotoxin. Lab. Invest. 66:347-361.

Hidalgo, A., J. Chang, J.E. Jang, A.J. Peired, E.Y. Chiang, and P.S. Frenette. 2009. Heterotypic interactions enabled by polarized neutrophil microdomains mediate thromboinflammatory injury. Nat. Med. 15:384-391. http://dx.doi.org/10.1038/nm.1939

Hirai, H., H. Sootome, Y. Nakatsuru, K. Miyama, S. Taguchi, K. Tsujioka, Y Ueno, H. Hatch, P.K. Majumder, B.S. Pan, and H. Kotani. 2010. MK2206, an allosteric Akt inhibitor, enhances antitumor efficacy by standard chemotherapeutic agents or molecular targeted drugs in vitro and in vivo. Mol. Cancer Ther. 9:1956-1967. http://dx.doi.org/10.1158/1535-7163 .MCT-09-1012

Katagiri, K., and T. Kinashi. 2012. Rap1 and integrin inside-out signaling. Methods Mol. Biol. 757:279-296. http://dx.doi.org/10.1007/978-1-61779-1666_18

Katagiri, K., A. Maeda, M. Shimonaka, and T. Kinashi. 2003. RAPL, a Rap1binding molecule that mediates Rap1-induced adhesion through spatial regulation ofLFA-1.Nat.Immunol. 4:741-748.http://dx.doi.org/10.1038/ ni950

Kumar, S., J. Xu, C. Perkins, F. Guo, S. Snapper, F.D. Finkelman, Y. Zheng, and M.D. Filippi. 2012. Cdc42 regulates neutrophil migration via crosstalk between WASp, CD11b, and microtubules. Blood. 120:3563-3574. http://dx.doi.org/10.1182/blood-2012-04-426981

Lakshmikanthan,S.,M.Sobczak,C.Chun,A.Henschel,J.Dargatz,R.Ramchandran, and M. Chrzanowska-Wodnicka. 2011. Rap1 promotes VEGFR2 activation and angiogenesis by a mechanism involving integrin $\alpha \mathrm{v} \beta_{3}$. Blood .118:2015-2026. http://dx.doi.org/10.1182/blood-2011-04-349282

Ley, K., C. Laudanna, M.I. Cybulsky, and S. Nourshargh. 2007. Getting to the site of inflammation: the leukocyte adhesion cascade updated. Nat. Rev Immunol. 7:678-689. http://dx.doi.org/10.1038/nri2156

Li, Y., J.Yan, P. De, H.C. Chang, A. Yamauchi, K.W. Christopherson II, N.C Paranavitana, X. Peng, C. Kim,V. Munugalavadla, et al. 2007. Rap1a null mice have altered myeloid cell functions suggesting distinct roles for the closely related Rap1a and 1b proteins. J. Immunol. 179:8322-8331. http://dx.doi.org/10.4049/jimmunol.179.12.8322
Linder, S., and M. Aepfelbacher. 2003. Podosomes: adhesion hot-spots of invasive cells. Trends Cell Biol. 13:376-385. http://dx.doi.org/10.1016/ S0962-8924(03)00128-4

Liu, X., B. Ma, A.B. Malik, H. Tang, T.Yang, B. Sun, G. Wang, R.D. Minshall, Y. Li, Y. Zhao, et al. 2012. Bidirectional regulation of neutrophil migration by mitogen-activated protein kinases. Nat. Immunol. 13:457-464. http://dx.doi.org/10.1038/ni.2258

Lou, L., J. Urbani, F. Ribeiro-Neto, and D.L. Altschuler. 2002. cAMP inhibition of Akt is mediated by activated and phosphorylated Rap1b. J. Biol. Chem. 277:32799-32806. http://dx.doi.org/10.1074/jbc.M201491200

M'Rabet, L., P. Coffer, F. Zwartkruis, B. Franke, A.W. Segal, L. Koenderman, and J.L. Bos. 1998. Activation of the small GTPase rap1 in human neutrophils. Blood. 92:2133-2140.

Mamdouh, Z., A. Mikhailov, and W.A. Muller. 2009. Transcellular migration of leukocytes is mediated by the endothelial lateral border recycling compartment. J. Exp. Med. 206:2795-2808. http://dx.doi.org/10.1084/ jem. 20082745

McMillan, S.J., R.S. Sharma, E.J. McKenzie, H.E. Richards, J. Zhang, A. Prescott, and P.R. Crocker. 2013. Siglec-E is a negative regulator of acute pulmonary neutrophil inflammation and suppresses CD11b $\beta 2-$ integrin-dependent signaling. Blood. 121:2084-2094. http://dx.doi. org/10.1182/blood-2012-08-449983

Muller,W.A. 2011. Mechanisms of leukocyte transendothelial migration. Annu. Rev. Pathol. 6:323-344. http://dx.doi.org/10.1146/annurev-pathol011110-130224

Nusrat, A., C.A. Parkos, T.W. Liang, D.K. Carnes, and J.L. Madara. 1997 Neutrophil migration across model intestinal epithelia: monolaver disruption and subsequent events in epithelial repair. Gastroenterology. 113:14891500. http://dx.doi.org/10.1053/gast.1997.v113.pm9352851

Nyström, A., Z.P. Shaik, D. Gullberg, T. Krieg, B. Eckes, R. Zent, A. Pozzi, and R.V. Iozzo. 2009. Role of tyrosine phosphatase SHP-1 in the mechanism of endorepellin angiostatic activity. Blood. 114:4897-4906. http:// dx.doi.org/10.1182/blood-2009-02-207134

Okrent, D.G., A.K. Lichtenstein, and T. Ganz. 1990. Direct cytotoxicity of polymorphonuclear leukocyte granule proteins to human lung-derived cells and endothelial cells. Am. Rev. Respir. Dis. 141:179-185. http:// dx.doi.org/10.1164/ajrccm/141.1.179

Petrache, I., A. Birukova, S.I. Ramirez, J.G. Garcia, and A.D. Verin. 2003. The role of the microtubules in tumor necrosis factor-alpha-induced endothelial cell permeability. Am. J. Respir. Cell Mol. Biol. 28:574-581. http://dx.doi.org/10.1165/rcmb.2002-0075OC

Phillipson, M., and P. Kubes. 2011. The neutrophil in vascular inflammation. Nat. Med. 17:1381-1390. http://dx.doi.org/10.1038/nm.2514

Phillipson, M., B. Heit, P. Colarusso, L. Liu, C.M. Ballantyne, and P. Kubes. 2006. Intraluminal crawling of neutrophils to emigration sites: a molecularly distinct process from adhesion in the recruitment cascade. J. Exp. Med. 203:2569-2575. http://dx.doi.org/10.1084/jem.20060925

Plitas, G., P.J. Gagne, B.E. Muhs, I.A. Ianus, J.P.Shaw, M. Beudjekian,Y.Delgado, G. Jacobowitz, C. Rockman, and P. Shamamian. 2003. Experimental hindlimb ischemia increases neutrophil-mediated matrix metalloproteinase activity: a potential mechanism for lung injury after limb ischemia. J. Am. Coll. Surg. 196:761-767. http://dx.doi.org/10.1016/S1072-7515 (03)00134-0

Raaijmakers, J.H., and J.L. Bos. 2009. Specificity in Ras and Rap signaling. J. Biol. Chem. 284:10995-10999. http://dx.doi.org/10.1074/jbc R800061200

Roberts, A.W., C. Kim, L. Zhen, J.B. Lowe, R. Kapur, B. Petryniak, A. Spaetti, J.D. Pollock, J.B. Borneo, G.B. Bradford, et al. 1999. Deficiency of the hematopoietic cell-specific Rho family GTPase Rac2 is characterized by abnormalities in neutrophil function and host defense. Immunity. 10:183-196. http://dx.doi.org/10.1016/S1074-7613(00)80019-9

Sage, P.T., and C.V. Carman. 2009. Settings and mechanisms for trans-cellular diapedesis. Front Biosci (Landmark Ed). 14:5066-5083. http://dx.doi.org/ $10.2741 / 3587$

Sasawatari, S., M. Yoshizaki, C. Taya, A. Tazawa, K. Furuyama-Tanaka, H. Yonekawa, T. Dohi, A.P. Makrigiannis, T. Sasazuki, K. Inaba, and N. Toyama-Sorimachi. 2010.The Ly49Q receptor plays a crucial role in neutrophil polarization and migration by regulating raft trafficking. Immunity. 32:200-213. http://dx.doi.org/10.1016/j.immuni.2010.01.012 
Schenkel, A.R., Z. Mamdouh, and W.A. Muller. 2004. Locomotion of monocytes on endothelium is a critical step during extravasation. Nat. Immunol. 5:393-400. http://dx.doi.org/10.1038/ni1051

Schwamborn, J.C., and A.W. Püschel. 2004. The sequential activity of the GTPases Rap1B and Cdc42 determines neuronal polarity. Nat. Neurosci. 7:923-929. http://dx.doi.org/10.1038/nn1295

Shimonaka, M., K. Katagiri, T. Nakayama, N. Fujita, T. Tsuruo, O. Yoshie, and T. Kinashi. 2003. Rap1 translates chemokine signals to integrin activation, cell polarization, and motility across vascular endothelium under flow. J. Cell Biol. 161:417-427. http://dx.doi.org/10.1083/jcb.200301133

Shulman, Z., V. Shinder, E. Klein, V. Grabovsky, O. Yeger, E. Geron, A Montresor, M. Bolomini-Vittori, S.W. Feigelson, T. Kirchhausen, et al. 2009. Lymphocyte crawling and transendothelial migration require chemokine triggering of high-affinity LFA-1 integrin. Immunity. 30:384396. http://dx.doi.org/10.1016/j.immuni.2008.12.020

Sikorski, E.E., R. Hallmann, E.L. Berg, and E.C. Butcher. 1993. The Peyer's patch high endothelial receptor for lymphocytes, the mucosal vascular addressin, is induced on a murine endothelial cell line by tumor necrosis factor-alpha and IL-1. J. Immunol. 151:5239-5250.

Stephens, L., C. Ellson, and P. Hawkins. 2002. Roles of PI3Ks in leukocyte chemotaxis and phagocytosis. Curr. Opin. Cell Biol. 14:203-213. http:// dx.doi.org/10.1016/S0955-0674(02)00311-3

Szczur, K., Y. Zheng, and M.D. Filippi. 2009. The small Rho GTPase Cdc42 regulates neutrophil polarity via CD11b integrin signaling. Blood. 114 4527-4537. http://dx.doi.org/10.1182/blood-2008-12-195164

Tremblay, G.M., E.Vachon, C. Larouche, and Y. Bourbonnais. 2002. Inhibition of human neutrophil elastase-induced acute lung injury in hamsters by recombinant human pre-elafin (trappin-2). Chest. 121:582-588. http:// dx.doi.org/10.1378/chest.121.2.582
Tsui, F.W., A. Martin, J. Wang, and H.W. Tsui. 2006. Investigations into the regulation and function of the $\mathrm{SH} 2$ domain-containing protein-tyrosine phosphatase, SHP-1. Immunol. Res. 35:127-136. http://dx.doi.org/10 .1385/IR:35:1:127

von Wedel-Parlow, M., S. Schrot, J. Lemmen, L. Treeratanapiboon, J. Wegener, and H.J. Galla. 2011. Neutrophils cross the BBB primarily on transcellular pathways: an in vitro study. Brain Res. 1367:62-76. http://dx.doi.org/ 10.1016/j.brainres.2010.09.076

Wittchen, E.S., A. Aghajanian, and K. Burridge. 2011. Isoform-specific differences between Rap1A and Rap1B GTPases in the formation of endothelial cell junctions. Small GTPases. 2:65-76. http://dx.doi.org/10 .4161/sgtp.2.2.15735

Yang, L., R.M. Froio, T.E. Sciuto, A.M. Dvorak, R. Alon, and F.W. Luscinskas 2005. ICAM-1 regulates neutrophil adhesion and transcellular migration of TNF-alpha-activated vascular endothelium under flow. Blood. 106: 584-592. http://dx.doi.org/10.1182/blood-2004-12-4942

Zemans, R.L., S.P. Colgan, and G.P. Downey. 2009. Transepithelial migration of neutrophils: mechanisms and implications for acute lung injury. Am J. Respir. Cell Mol. Biol. 40:519-535. http://dx.doi.org/10.1165/rcmb 2008-0348TR

Zhang, H., F. Meng, C.L. Chu, T. Takai, and C.A. Lowell. 2005. The Src family kinases Hck and Fgr negatively regulate neutrophil and dendritic cell chemokine signaling via PIR-B. Immunity. 22:235-246. http://dx.doi .org/10.1016/j.immuni.2005.01.004

Zhang, H., U.Y. Schaff, C.E. Green, H. Chen, M.R. Sarantos, Y. Hu, D. Wara, S.I. Simon, and C.A. Lowell. 2006. Impaired integrin-dependent function in Wiskott-Aldrich syndrome protein-deficient murine and human neutrophils. Immunity. 25:285-295. http://dx.doi.org/10.1016/ j.immuni.2006.06.014 